ARTICLE

\title{
Rapid proliferation due to better metabolic adaptation results in full virulence of a filament- deficient Candida albicans strain
}

Christine Dunker (10) 1, Melanie Polke ${ }^{1,5}$, Bianca Schulze-Richter (10) 1,6, Katja Schubert', Sven Rudolphi (1) 1, A. Elisabeth Gressler (1) 1,6, Tony Pawlik (10) 1, Juan P. Prada Salcedo ${ }^{2}$, M. Joanna Niemiec (1) 1, Silvia Slesiona-Künzel ${ }^{1}$, Marc Swidergall (1) ${ }^{3}$, Ronny Martin (1) ${ }^{4}$, Thomas Dandekar (10 ${ }^{2} \&$ Ilse D. Jacobsen (10) ${ }^{1 凶}$

The ability of the fungal pathogen Candida albicans to undergo a yeast-to-hypha transition is believed to be a key virulence factor, as filaments mediate tissue damage. Here, we show that virulence is not necessarily reduced in filament-deficient strains, and the results depend on the infection model used. We generate a filament-deficient strain by deletion or repression of EED1 (known to be required for maintenance of hyphal growth). Consistent with previous studies, the strain is attenuated in damaging epithelial cells and macrophages in vitro and in a mouse model of intraperitoneal infection. However, in a mouse model of systemic infection, the strain is as virulent as the wild type when mice are challenged with intermediate infectious doses, and even more virulent when using low infectious doses. Retained virulence is associated with rapid yeast proliferation, likely the result of metabolic adaptation and improved fitness, leading to high organ fungal loads. Analyses of cytokine responses in vitro and in vivo, as well as systemic infections in immunosuppressed mice, suggest that differences in immunopathology contribute to some extent to retained virulence of the filamentdeficient mutant. Our findings challenge the long-standing hypothesis that hyphae are essential for pathogenesis of systemic candidiasis by C. albicans.

\footnotetext{
${ }^{1}$ Research Group Microbial Immunology, Leibniz Institute for Natural Product Research and Infection Biology - Hans Knoell Institute, Beutenbergstraße 11a Jena, Germany. ${ }^{2}$ Department of Bioinformatics, Biocenter, Am Hubland, University of Würzburg, Würzburg, Germany. ${ }^{3}$ The Lundquist Institute for Biomedical Innovation at Harbor UCLA Medical Center, David Geffen School of Medicine at UCLA, Los Angeles, CA, USA. ${ }^{4}$ Institute for Hygiene and Microbiology, University of Würzburg, Würzburg, Germany. ${ }^{5}$ Present address: Laboratory Dr. Wisplinghoff, Department of Molecular Biology, Horbeller Strasse 18-20, Cologne, Germany. ${ }^{6}$ Present address: Institute of Immunology, Molecular Pathogenesis, Center for Biotechnology and Biomedicine (BBZ), College of Veterinary Medicine, Leipzig University, Deutscher Platz 5, Leipzig, Germany. ${ }^{凶}$ email: ilse.jacobsen@hki-jena.de
} 
T he polymorphic yeast Candida albicans colonizes up to $70 \%$ of the human population as a commensal on mucosal surfaces $^{1,2}$. As an opportunistic fungal pathogen, however, C. albicans is able to cause superficial as well as life-threatening systemic infections promoted by disturbances in the microbiota and impaired host defenses 3,4 . Despite antifungal therapy, disseminated candidiasis is associated with high mortality rates of up to $50 \%{ }^{5,6}$.

The reversible transition of spherical budding yeast to pseudohyphal or hyphal filaments is promoted in vivo by body temperature, serum, physiological $\mathrm{pH}$ and elevated $\mathrm{CO}_{2}$ concentration ${ }^{7,8}$. Nevertheless, both morphologies are present in tissues during systemic infection ${ }^{9}$. While filaments facilitate tissue invasion, damage and escape from host cells ${ }^{10,11}$, yeast cells are believed to be important for mucosal colonization, dissemination through the bloodstream, adherence to endothelial cells and biofilm formation ${ }^{12}$. Furthermore, yeast and hypha are recognized differentially by immune cells ${ }^{13}$. Saville et al. dissected the relative contribution of $C$. albicans filamentation to virulence during systemic infection by using a regulable expression system, placing one copy of the negative regulator of filamentation NRG1 under the control of a tetracycline-regulable promotor ${ }^{14}$. Mice challenged intravenously with the tet-NRG1 strain succumbed to infection when hyphal growth was permitted but survived when fungal cells were enforced to grow in the yeast form. Similarly, other C. albicans yeast-locked mutants, such as the $c p h 1 \Delta / \Delta$ efg $1 \Delta / \Delta$ double and $h g c 1 \Delta / \Delta$ mutant have been shown to be avirulent or are strongly attenuated in virulence ${ }^{15,16}$. On the other hand, mutants locked in the filamentous form like $t u p 1 \Delta / \Delta$ or $n r g 1 \Delta / \Delta$ are less virulent as well ${ }^{17-19}$, implying that morphological plasticity is essential for virulence in murine disseminated candidiasis.

One of the factors required for maintenance of hyphal growth, invasion and damage of $C$. albicans is encoded by EED1 (Epithelial Escape and Dissemination $1^{7,20}$ ). A homozygous eed $1 \Delta / \Delta$ deletion mutant is still able to initiate germ tube formation, but fails to elongate these into hypha and eventually switches back to yeast cell growth ${ }^{7,20,21}$. Here we show that the eed $1 \Delta / \Delta$ mutant is fully virulent in a murine model of systemic candidiasis and confirmed this finding using a tetracycline-regulable expression system to induce or repress EED1 in C. albicans in vivo. Virulence of these filament-deficient mutants is associated with high yeast proliferation rates in vivo and enhanced growth in vitro on nutrient sources likely encountered in the host, suggesting metabolic adaptation as the underlying mechanism for retained virulence in the absence of filamentation. Analysis of host responses furthermore supports a contribution of altered immunopathology to $C$. albicans virulence in the absence of filamentation.

\section{Results}

$E E D 1$ is required for virulence in a murine intraperitoneal infection model. Hypha formation has been shown to be essential for tissue invasion and damage in vitro and in vivo ${ }^{11,14,22}$. Consistent with this, the eed $1 \Delta / \Delta$ mutant, unable to maintain hyphal growth, was not able to damage renal, hepatic and oral epithelial cells in vitro within $24 \mathrm{~h}$ of co-incubation (Fig. 1a). To assess the impact of EED1 for tissue invasion and damage in vivo, we employed an intraperitoneal infection model. In this model, $C$. albicans filamentation facilitates invasion from the peritoneal cavity into intraperitoneal organs such as liver, spleen and pancreas ${ }^{23}$. In line with the in vitro results, deletion of EED1 led to reduced damage of liver and pancreatic tissue indicated by lower serum levels of tissue-specific enzymes and lower clinical scores compared to mice infected with the wild type strain
(WT; Supplementary Fig. 1). This attenuated virulence phenotype was confirmed using a conditional knock out mutant (t-EED1), in which one EED1 allele was deleted and the other was placed under the control of a tet-OFF promoter ${ }^{14}$. In the presence of doxycycline $(\mathrm{t}-\mathrm{EED} 1+)$, repressed EED1 expression leads to yeast cell growth. In absence of doxycycline (t-EED1-), the gene is constitutively expressed resulting in increased filamentation on solid media (Supplementary Fig. 2a) and filamentation comparable to the WT in liquid media (Supplementary Fig. 2b). In the presence of doxycycline, mice developed significantly less clinical symptoms after intraperitoneal infection with the t-EED1+ yeast compared to the WT and the t-EED1- filamentous strain $24 \mathrm{~h}$ post infection (p.i.) (Fig. 1b). Histological analysis showed $\mathrm{t}$-EED1+ yeast that remained in the upper tissue layers below the liver capsule whereas WT and t-EED1- hyphae invaded deeply into liver parenchyma (Fig. 1c). Furthermore, infection with WT and t-EED1 - induced significantly increased serum levels of alanine aminotransaminase (ALT) and pancreatic amylase indicating liver and pancreatic injury, respectively (Fig. 1d). In contrast, reduced tissue invasion of the t-EED1+ yeast resulted in serum enzyme levels of ALT and pancreatic amylase comparable to the uninfected control. Interestingly, a significantly higher fungal burden was recovered from liver tissue of mice infected with either the t-EED1+ or eed $1 \Delta / \Delta$ mutant compared to the respective WT (Fig. 1e and Supplementary Fig. 1c). Thus, tissue damage and clinical symptoms correlated with the ability to form hyphae in the intraperitoneal infection model, and deletion or repression of EED1 resulted in attenuation of virulence despite a higher liver fungal burden.

Deletion of EED1 affects dissemination from the gastrointestinal tract in immunosuppressed mice. It is generally believed that the gastrointestinal tract is the main reservoir for $C$. albicans in humans ${ }^{24,25}$. In order to disseminate systemically, the fungus needs to translocate across the mucosal barrier ${ }^{24,25}$. Consistent with the in vitro results for renal, hepatic and oral epithelial cells, deletion of EED1 significantly reduced the ability of $C$. albicans to damage enterocytes under normoxic and hypoxic conditions (Fig. 2a), resulting in maintained barrier function and reduced translocation in vitro (Fig. 2b, c). Colonization of the intestinal tract was moderately increased for eed $1 \Delta / \Delta$ compared to the WT in antibiotic-treated immunocompetent mice, but not in mice treated with cyclophosphamide (Fig. 2d, e). Dissemination of the eed $1 \Delta / \Delta$ mutant to internal organs was, however, only observed upon cyclophosphamide treatment (Fig. 2f), where a significantly higher number of colony forming units (CFU) in kidneys were observed for eed $1 \Delta / \Delta$ compared to the WT. Of note, while cyclophosphamide reduces the numbers of immune cells and also impacts the intestinal barrier function 26,27 , we did not observe any symptoms of disseminated disease in the mice. This suggests that the treatment was not sufficient to induce the level of immunosuppression and/ or intestinal damage required for translocation of a sufficiently high number of fungal cells to cause disease ${ }^{27}$. Nonetheless, these results support the concept that growth in the yeast form is beneficial for intestinal colonization ${ }^{28,29}$ (at least in immunocompetent mice) and dissemination ${ }^{12}$, but that filamentation is required for active translocation ${ }^{22}$.

EED1 is not essential for virulence in a systemic infection model. Based on the in vitro data and results from the intraperitoneal infection model, we expected the EED1 mutants also to be attenuated in a murine systemic (intravenous) infection model that mimics catheter-associated disseminated candidiasis in humans. Surprisingly, the eed $1 \Delta / \Delta$ mutant showed enhanced 
a
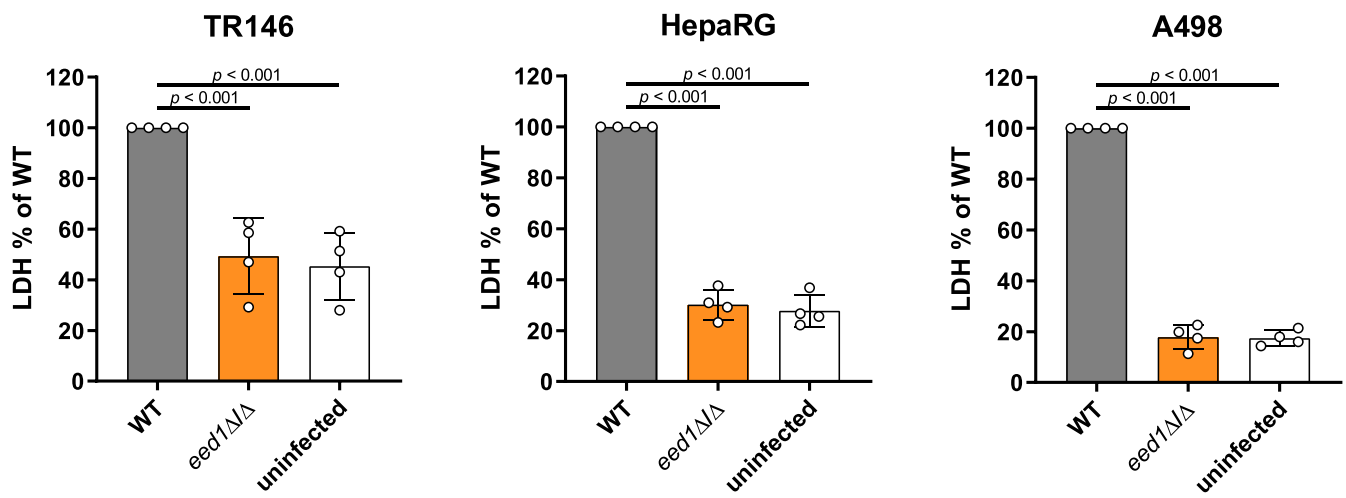

b

C
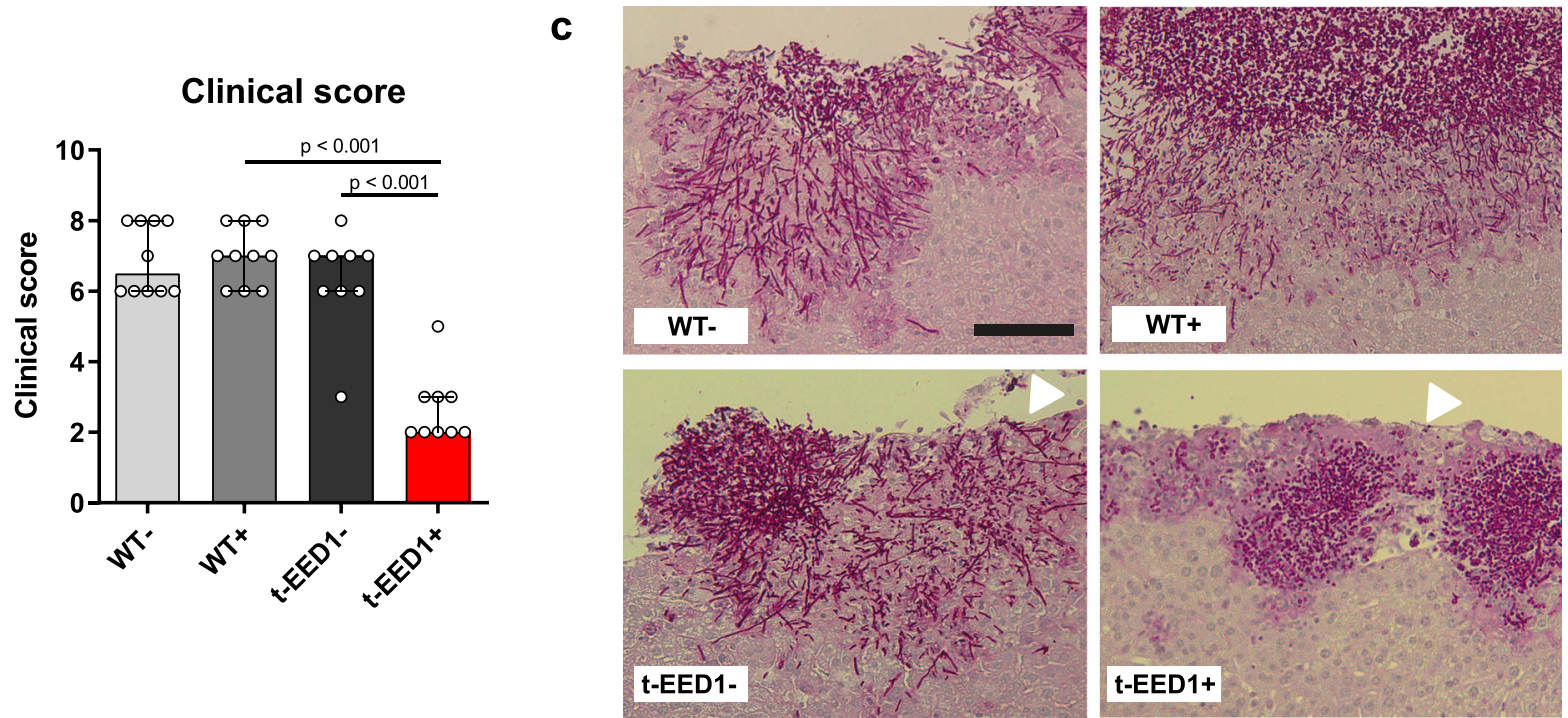

d
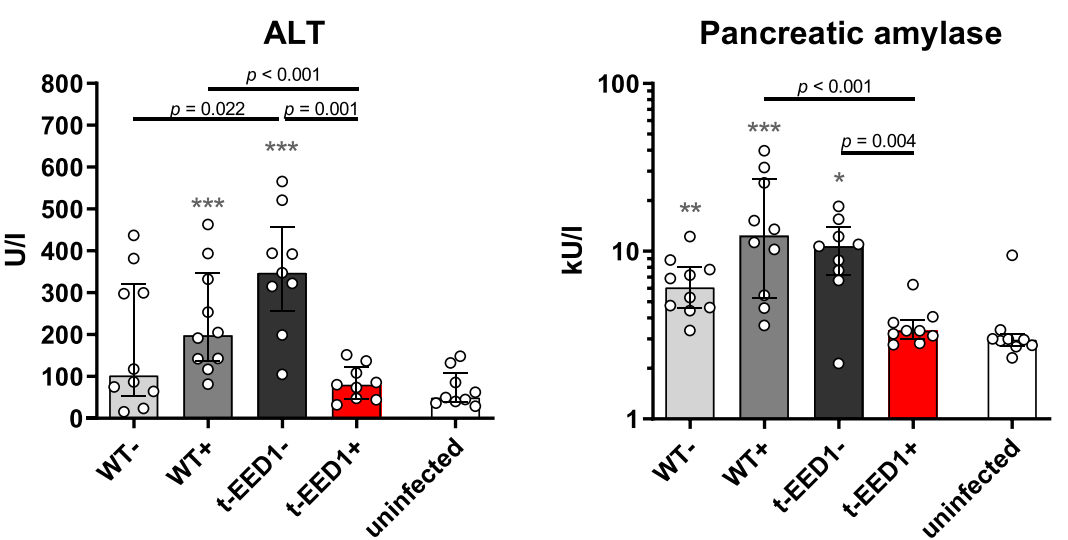

e

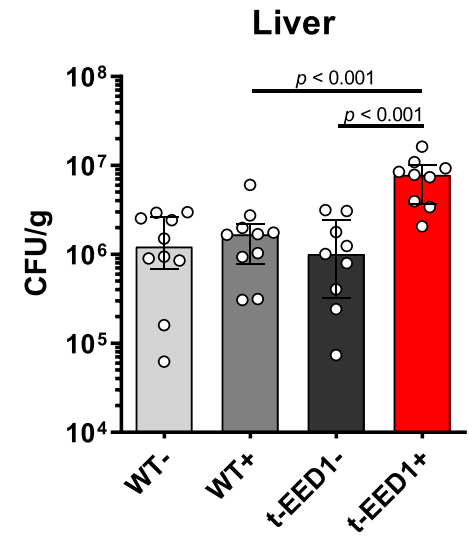

virulence compared to the WT when low infectious doses were used (Fig. 3a) whereas with a high infectious dose mortality was delayed for t-EED1 + yeast (Fig. 3b). Intermediate infectious doses led to virulence and disease progression indistinguishable to the WT when t-EED1 was either forced to grow as yeast or as hyphae (Fig. 3c, Supplementary Fig. 3). Histology confirmed that t-EED1 + grew as yeast in vivo (Fig. 3d). Consistent with previous reports, experiments conducted in parallel with the tetNRG1 strain ${ }^{14}$ resulted in clinical disease only when filamentation was facilitated by the presence of doxycycline (Supplementary Fig. $\left.4 a-c^{14}\right)$. We also noted that mice infected with the WT (THE1-CIp10) reached humane endpoints earlier when receiving doxycycline; this is likely a consequence of lower water uptake in these groups (see method section for details). Determination of CFU in mice infected with the intermediate dose showed similar initial fungal burden $6 \mathrm{~h}$ p.i. in kidney, liver, brain and spleen (Fig. 3e). However, already $24 \mathrm{~h}$ p.i. we observed significantly increased ( 25 -fold higher) fungal burden in the kidneys of mice infected with t-EED1 + yeast compared to the filamentous strains. Likewise, fungal burden increased for tet-NRG1- yeast, reaching significantly higher levels $72 \mathrm{~h}$ p.i. compared to the WT-, but in comparison to t-EED1 + yeast declined until the end of the experiment (Supplementary Fig. 4d). Furthermore, fungal burden of t-EED1 + yeast in the brain continued to increase until mice 
Fig. 1 Hyphal elongation of $\boldsymbol{C}$. albicans is required for tissue damage in vitro and virulence in an intraperitoneal infection model. a Damage of oral (TR146), hepatic (HepaRG) and renal (A498) epithelial cells was quantified by measuring the release of lactate dehydrogenase (LDH) into the supernatant after co-incubation for $24 \mathrm{~h}$ with WT (SC5314) or eed1 $/ \Delta$ mutant. Uninfected cells served as negative control. LDH released by WT was set to $100 \%$. Data are presented as mean \pm SD from four biologically independent experiments. Within each experiment, supernatants from three wells infected by the same strain were pooled and LDH was measured. Data was analyzed by two-tailed students $t$-test. $\mathbf{b}$-e t-EED1 + yeasts are attenuated in invasion, damage and virulence potential despite higher organ fungal loads in the intraperitoneal infection model $24 \mathrm{~h}$ post infection. Mice were infected intraperitoneally with $1 \times 10^{8}$ cells of WT (THE1-CIp10) or t-EED1 in the presence $(+)$ or absence $(-)$ of doxycycline supplied via the drinking water. Data derived from two independent experiments, WT - and WT $n=10, \mathrm{t}-\mathrm{EED} 1$ - and t-EED1 $n=9$ animals per group. $\mathbf{b}$ Repression of EED1 by doxycycline led to significantly reduced clinical symptoms in mice. The semiquantitative clinical score was determined by assessing fur, coat and posture, behavior and lethargy, fibrin exudation and other symptoms like diarrhea. The score ranges from 0 (no symptoms) to 10 (severe illness). c Representative images of periodic acid-Schiff stained histological sections of liver tissue $24 \mathrm{~h} \mathrm{p.i.,} \mathrm{fungal} \mathrm{cells} \mathrm{are} \mathrm{stained} \mathrm{purple.} \mathrm{Arrows} \mathrm{point} \mathrm{towards} \mathrm{the} \mathrm{liver} \mathrm{surface} \mathrm{(capsule,} \mathrm{partially} \mathrm{destroyed).}$ The scale bar represents $100 \mu \mathrm{m}$ and applies to all images. d Damage of liver and pancreas was quantified by measuring serum levels of alanine aminotransaminase (ALT) and pancreatic amylase, respectively. Enzyme levels of uninfected mice $(n=9)$ served as negative control. e Fungal burden in the liver. b, d, e Median and interquartile range are shown, two-sided Mann-Whitney test. Asterisks above bars represent significant differences compared to the uninfected control ${ }^{\star} p \leq 0.05 ;{ }^{\star \star} p \leq 0.01 ;{ }^{\star \star \star} p \leq 0.001$. Source data are provided as a Source Data file.

became moribund, whereas after infection with filamentous strains cell numbers peaked $24 \mathrm{~h}$ p.i. and were stable or declined thereafter. After an initial decline, the CFU of the t-EED1 + yeast stabilized and increased in liver and spleen while they continuously declined after infection with the WT, t-EED1- or tetNRG1 yeast or hypha (Fig. 3e; Supplementary Fig. 4d). To test the possibility that differences in fungal load were due to the underestimation of CFU plated from filamentous C. albicans strains, we performed quantitative PCR targeting the C. albicans $18 \mathrm{~S}$ rRNA gene RDN18 in complex DNA isolated from infected kidney homogenates ${ }^{30}$. A strong correlation $\left(R^{2}=0.7076\right)$ between CFU count and DNA content irrespective of the fungal morphology (Supplementary Fig. 5) supports the CFU results.

During hematogenously disseminated candidiasis EED1 deficiency leads to delayed renal cytokine production but increased immune cell infiltration at later time points. We hypothesized that the increased fungal burden observed for t-EED1 + yeast could be the result of an altered early innate immune response leading to reduced fungal killing. Therefore, we quantified immune cells in the kidney over the course of infection. Leukocytes started to infiltrate kidneys $24 \mathrm{~h}$ p.i. and no difference was observed in the overall number or subpopulations of leukocytes 24 and $48 \mathrm{~h}$ p.i. between WT + and t-EED1 + yeast (Supplementary Figs. 6-7). However, morphology-dependent significant differences between WT + and t-EED1+ were observed $72 \mathrm{~h}$ p.i.: Total leukocyte numbers were approximately 2-fold higher in response to t-EED1+ yeast (Fig. 4a), with increased numbers of monocytes (4.5-fold), macrophages (3.2-fold) and DCs and NK cells (2-fold). This coincided with 190-fold higher yeast fungal burden compared to WT+ (Fig. 3e). Interestingly, significantly less leukocytes accumulated in kidneys after infection with the tEED1 - filamentous strain compared to WT- (Supplementary Fig. 8), despite comparable CFU 72 h p.i. (Fig. 3e). While renal cytokine levels induced by the filamentous t-EED1 - were comparable to the WT- throughout the course of infection (Supplementary Figs. 9-10), less pro-inflammatory cytokines were induced by $\mathrm{t}$-EED $1+$ yeast than by WT $+24 \mathrm{~h}$ p.i. (Fig. $4 \mathrm{~b}$ ), despite higher fungal burden of t-EED1+ yeast. In contrast, cytokine levels were comparable $48 \mathrm{~h}$ p.i., and a tendency towards increased cytokine release, with significant higher amounts of IL18, IP-10, RANTES and IFN-y in response to t-EED1+ yeast, was observed $72 \mathrm{~h}$ p.i. (Fig. 4b). In moribund mice no morphologydependent difference in cytokine levels was observed (Supplementary Fig. 10). To investigate whether the local differences in renal cytokine production were reflected by differences in systemic inflammation, we determined serum levels of the sepsis markers soluble triggering receptor expressed on myeloid cells
(sTREM-1) and neutrophil gelatinase-associated lipocalin (NGAL). NGAL and sTREM-1 levels increased rapidly and throughout the course of infection (Fig. 4c) irrespective of the fungal morphology.

Lower cytokine levels induced by t-EED1+ yeast in the presence of similar leukocyte numbers $24 \mathrm{~h}$ p.i. suggested differences in the interaction with leukocytes and/or epithelial cells and their interaction with fungal cells was therefore analyzed in vitro. Murine bone marrow (BM) neutrophils and BM-derived macrophages (BMDMs) were capable of phagocytosing and killing $C$. albicans WT and eed $1 \Delta / \Delta$ mutant to the same extent in vitro after $1 \mathrm{~h}$ and $2 \mathrm{~h}$, respectively (Fig. 5a, b; Supplementary Fig. 11a). At that time point both strains had formed germ tubes (Supplementary Fig. 11b and Supplementary Fig. 12). After $6 \mathrm{~h}$, the WT maintained filamentation while the eed $1 \Delta / \Delta$ mutant had switched back to yeast cell growth (Fig. 5c; Supplementary Fig. 12). Analysis at $6 \mathrm{~h}$ showed that a significantly larger proportion of $C$. albicans eed $1 \Delta / \Delta$ was killed by BMDMs compared to the WT. However, we noted that the relative increase in CFU of the eed $1 \Delta / \Delta$ mutant from $0 \mathrm{~h}$ to $6 \mathrm{~h}$ was considerably higher than for the WT both in the presence and absence of macrophages (Fig. 5d). This resulted in significantly higher numbers of eed $1 \Delta / \Delta$ than WT cells in the presence of BMDMs. In addition, the eed $1 \Delta / \Delta$ mutant showed a reduced capacity to damage BMDMs (Fig. 5e) and to stimulate TNF- $\alpha$ release by BMDMs $24 \mathrm{~h}$ p.i. (Fig. 5f). At that time wells that contained the $C$. albicans WT were completely covered by hyphae whereas wells with eed $1 \Delta / \Delta$ showed yeasts only and macrophages were visible from time to time (Supplementary Fig. 12). In contrast, activation of murine PMNs determined by the release of IL-10, IL-6 and TNF- $\alpha$ (Supplementary Fig. 11c) and production of reactive oxygen species (ROS; Supplementary Fig. 11d) was comparable between the strains. Infection of renal, hepatic and oral epithelial cells with the eed $1 \Delta / \Delta$ mutant induced no increase of pro-inflammatory cytokines compared to uninfected controls (Fig. 5g), likely due to the lack of damage caused by the mutant in this model (Fig. 1a). For oral epithelial cells, no significant increase was observed for the WT either, although a tendency of higher cytokine production was observed. Thus, the initial lower cytokine release in response to t-EED1+ yeast in vivo is likely due to reduced damage of and lower cytokine production by renal and hepatic cells and macrophages, which is balanced by the response of recruited immune cells at later time points.

eed $1 \Delta / \Delta$ yeast display enhanced growth on physiologically relevant carbon sources. EED1 depleted yeast were able to increase their cell number approximately 100-fold from $6 \mathrm{~h}$ to 24 $\mathrm{h}$ p.i. in murine kidneys (which equals a generation time of $2.6 \mathrm{~h}$ 
a

Damage

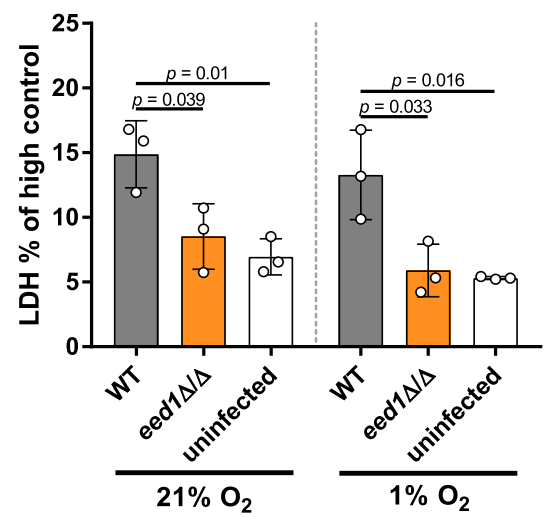

b

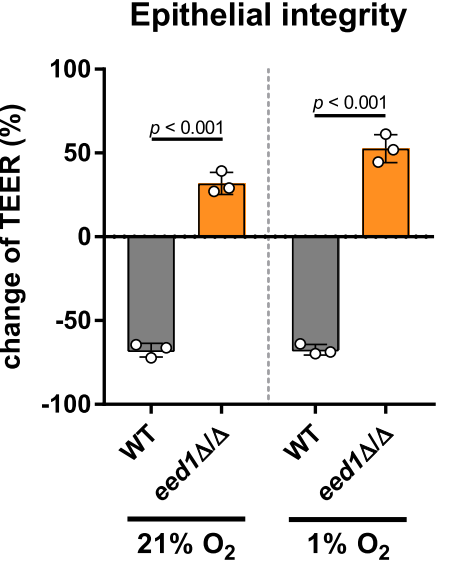

C

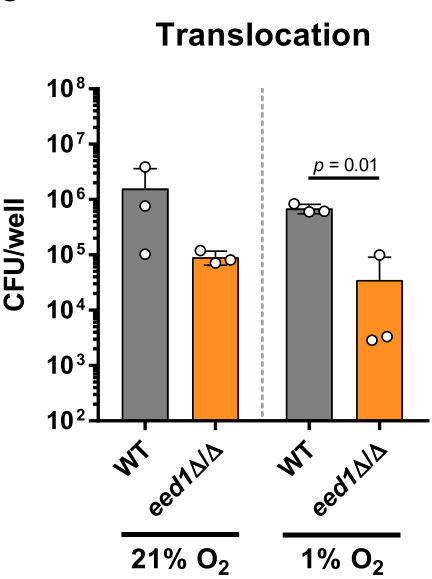

d

Immunocompetent

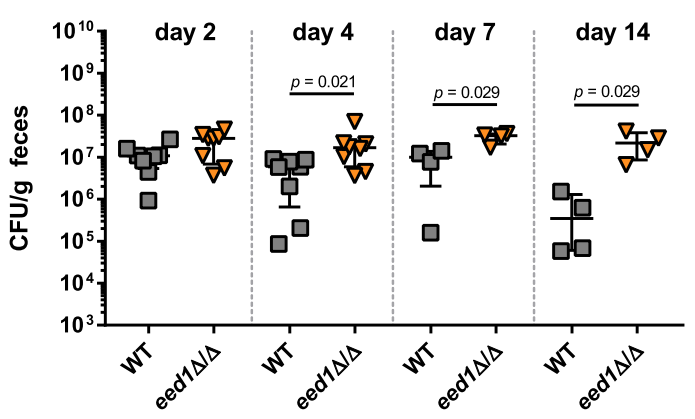

Immunocompromised

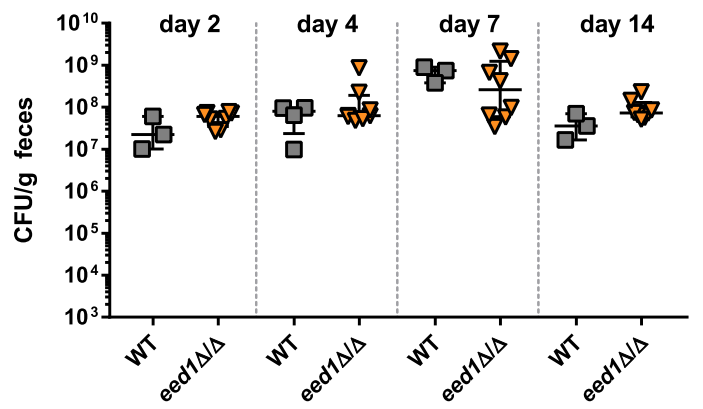

e

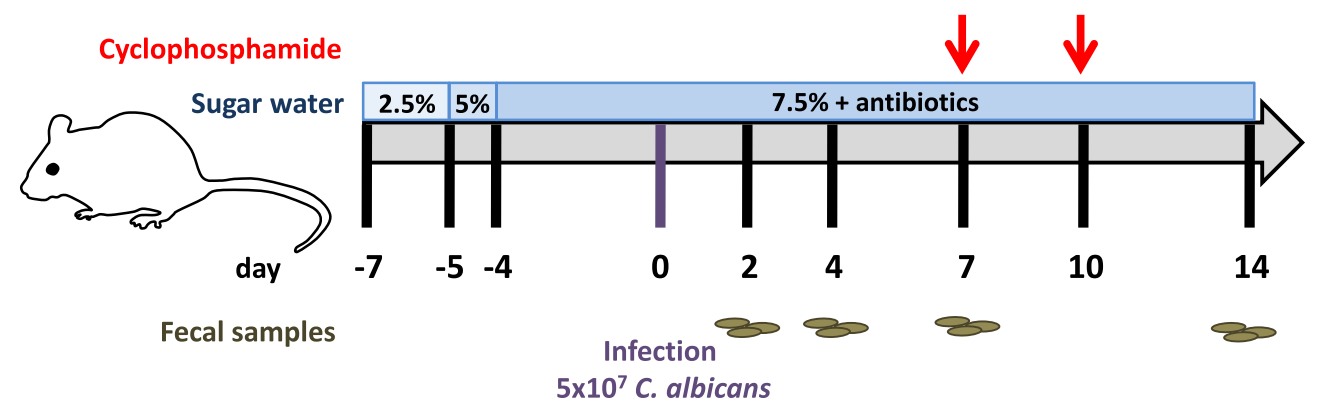

f
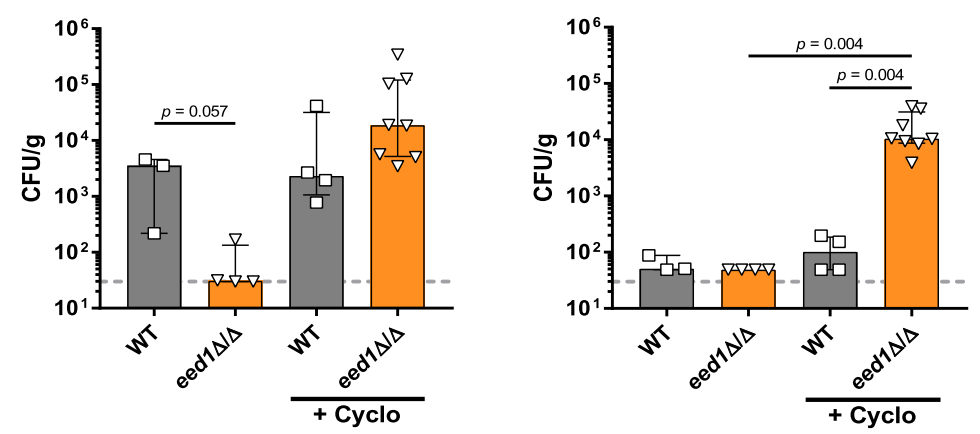

compared to $7.1 \mathrm{~h}$ for the WT). Since we found no evidence for reduced recognition or killing by immune cells, this observation cannot be explained by increased immune evasion resulting in less killing. We thus hypothesized that EED1-deficient yeasts are metabolically better adapted to acquire locally available nutrients resulting in increased proliferation. Therefore, we analyzed the growth of $C$. albicans WT and the eed $1 \Delta / \Delta$ mutant in the presence of different fermentable and non-fermentable carbon sources at $37^{\circ} \mathrm{C}$ (Fig. 6). Growth of both strains was similar with $2 \%$ glucose in complex (YPD) and defined media (SD). However, in the presence of physiological glucose concentrations of $0.1 \%$ in SD medium, the mutant reached lower cell densities at stationary phase. In YPD with $0.1 \%$ glucose, in contrast, the eed $1 \Delta / \Delta$ mutant continued to grow steadily after depletion of glucose 


\section{Fig. 2 The eed1 $\Delta / \Delta$ mutant shows a reduced translocation capacity in vitro and in a gut dissemination model in immunocompetent but not in}

immunocompromised mice. a-c $\mathrm{C} 2 \mathrm{BBe} 1$ cells were infected with $\mathrm{C}$. albicans WT (SC5314) or the eed $1 \Delta / \Delta$ mutant and incubated under normoxic (21\% $\mathrm{O}_{2}$ ) or hypoxic $\left(1 \% \mathrm{O}_{2}\right)$ conditions for $24 \mathrm{~h}$. a Damage of $\mathrm{C} 2 \mathrm{BBe} 1$ cells was quantified by measurement of $\mathrm{LDH}$ and is shown in \% of high control (cells lysed with Triton X-100). Uninfected cells served as negative control. b Integrity of epithelial barrier was quantified by TEER measurement. Data are expressed as change of TEER $24 \mathrm{~h}$ post infection compared to TEER values prior to infection in percent. c Translocation across the epithelial barrier was assessed by CFU plating. a-c Graphs show the mean \pm SD of three independent biological replicates, two-tailed students $t$-test. $p$-values are shown in the graph. $\mathbf{d}$ Fungal burden in feces of antibiotic-treated immunocompetent and mice rendered immunocompromised by cyclophosphamide treatment. Immunocompetent, day 2 and $4 n=8$; day 7 and $14 n=4$ mice per group, one experiment. Immunocompromised WT infected $n=3$; eed $1 \Delta / \Delta n=8$, one experiment. e Schematic overview of the timeline for the gastrointestinal dissemination model. $\mathbf{f}$ Fungal burden in liver (left) and kidneys (right) of immunocompetent or cyclophosphamide-treated immunosuppressed (+Cyclo) mice colonized with either $\mathrm{C}$. albicans WT or eed1 $\Delta / \Delta$ mutant $14 \mathrm{~d}$ post infection. WT $n=3$, one experiment; WT + Cyclo and eed $1 \Delta / \Delta n=4$, one experiment; eed1 $\Delta / \Delta+$ Cyclo $n=8$ mice, data from two independent experiments. Dashed lines indicate limit of detection. d, f Shown is the median with interquartile range, two-sided Mann-Whitney test, $p$-values are shown in the graph. Source data are provided as a Source Data file.

reaching higher ODs than the WT. Importantly, the eed $1 \Delta / \Delta$ mutant showed enhanced growth in the presence of the physiological relevant alternative carbon sources lactate, acetate, citrate, amino acids and the amino sugar $\mathrm{N}$-acetyl-glucosamine (GlcNAc). Additionally, the eed $1 \Delta / \Delta$ mutant showed faster onset of growth in YCB-BSA compared to the WT indicating that this strain is highly proteolytically active. Furthermore, eed $1 \Delta / \Delta$ showed better growth than the WT in murine kidney homogenates. Taken together, these data suggest that the absence of EED1 results in better metabolic adaptation in vivo, facilitating faster proliferation resulting in increased fungal burden.

To gain information on possible mechanisms mediating the enhanced proliferation of the eed $1 \Delta / \Delta$ mutant on alternative carbon sources, we performed RNAseq analysis of cells grown in $\mathrm{SD}$ with glucose at $30^{\circ} \mathrm{C}$ for $10 \mathrm{~h}$ (designated as $0 \mathrm{~h}$ time point), followed by a shift to citrate or casamino acids as sole carbon source at $37^{\circ} \mathrm{C}(2 \mathrm{~h}, 6 \mathrm{~h}$, and $12 \mathrm{~h}$; Supplementary Fig. 13a). Growth in SD with glucose resulted in yeast morphology for both strains (Supplementary Fig. 13b); on casamino acids, both strains formed germ tubes within $2 \mathrm{~h}$, but only the WT formed hyphae at later time points (Supplementary Fig. 13b). With citrate as sole carbon source, filamentation was observed only for the WT (Supplementary Fig. 13b). In both, citrate and amino acid media, the eed $1 \Delta / \Delta$ mutant showed enhanced growth as observed by optical density as well as by determination of dry weight (Supplementary Fig. 14a). Principal component analysis (PCA) of the RNAseq data showed that biological replicates clustered together and that the transcriptome of both strains varied over time (Supplementary Fig. 14b). Comparison of eed $1 \Delta / \Delta$ mutant and WT for each condition and time point (with a $\log _{2}$ fold change of 2.0 as cut off) revealed that only one yet uncharacterized gene (orf19.2962) was differentially expressed during yeast growth at the $0 \mathrm{~h}$ time point (2.1-fold down-regulated). After the shift to media containing either citrate or casamino acids as sole carbon sources, relatively few genes $(<320)$ were differentially expressed in the mutant compared to the WT at any given time point, and the majority of differentially expressed genes (DEGs) were down-regulated in eed $1 \Delta / \Delta$ compared to the WT (Supplementary Fig. 15). Consistent with differences in morphology, down-regulated genes in both conditions included genes associated with filamentous growth, biofilm formation, and adhesion (e.g. ECE1, HGC1, BRG1, UME6, HYR1, SAP5, HWP1 and ALS1; Supplementary Fig 16a). The expression of secreted aspartyl proteinases likewise coincided with morphology, with the hypha-associated genes SAP4- $6^{31}$ showing reduced transcription while transcription of the yeast-associated genes $S A P 1$ and $S A P 3^{31}$ was enhanced in the eed $1 \Delta / \triangle$ mutant during growth on casamino acids (Supplementary Fig. 16b). The highest number of DEGs was observed at the $12 \mathrm{~h}$ time point (Fig. 7a), when the eed $1 \Delta / \Delta$ mutant grew as yeast but also the filamentous WT switched back to yeast cell growth to some extent (Fig. 7b). Genes that were up-regulated in eed $1 \Delta / \Delta$ mutant compared to WT in both media included the ammonium permease $M E P 1$, the putative 2-isopropylmalate synthase LEU4, the secreted yeast wall protein $Y W P 1$, the transcription factor MSS11, and 5 yet uncharacterized open reading frames. Most of the DEGs showed a medium-specific regulation. After $12 \mathrm{~h}$ of growth with citrate as sole carbon source Gene Ontology (GO) term analysis identified enrichment of genes associated with organic acid, (long-chain) fatty acid and small molecule biosynthetic and metabolic processes within the up-regulated DEGs in the eed $1 \Delta / \Delta$ mutant (Fig. 7c), which might explain the better growth of the mutant on citrate. Genes that were up-regulated exclusively in citrate included e.g., the dicarboxylic acid transporter JEN2 and a key enzyme of gluconeogenesis, PCK1. Of note, the only significantly enriched GO term after $12 \mathrm{~h}$ of growth on casamino acids in the genes up-regulated in eed $1 \Delta / \Delta$ was found to be carbohydrate transport. However, individual genes that were significantly upregulated included the broad specificity amino acid permease GAP2, the predicted amino acid transmembrane transporter $U G A 5$, the GATA-type transcription factor GAT1 that regulates nitrogen utilization, and the glyoxylate cycle enzyme isocitrate lyase ICL1 (Supplementary Data 1), which might contribute to enhanced growth. In addition to GAT1, three other transcription factors (TFs) were up-regulated and 13 down-regulated in the eed $1 \Delta / \Delta$ mutant $12 \mathrm{~h}$ after shift to either citrate of casamino acids (Supplementary Fig. 16c). Several down-regulated TFs were associated with filamentous growth and thus, differential expression likely reflects differences in morphology (e.g., UME6, SFL2, BRG1, TEC1, OFI1 ${ }^{32}, A C E 2^{33}$ ). Counterintuitively, though, transcription of MSS11, encoding a factor interacting with Flo8 to activate transcription of hypha-specific genes ${ }^{34}$, was higher in the mutant in both citrate and amino acid media. Similarly, expression of $R F X 2$ was reduced in the eed $1 \Delta / \Delta$ mutant deletion of this gene, however, results in hyper-filamentation and increased expression of hypha-associated genes ${ }^{35}$. Interestingly, both WOR1 and WOR3 were significantly down-regulated after prolonged growth in both media, possibly indicating increased commitment of the eed $1 \Delta / \Delta$ mutant to grow as white cells. White cells have been shown to have a metabolic advantage over opaque cells with various nutrients at $37^{\circ} \mathrm{C}^{36}$, lead to higher renal fungal burden, and are more virulent in systemic infection models 37,38 .

High numbers of yeast cells result in renal damage in vivo. To determine if immune cell recruitment together with high fungal burden during t-EED1 + infection was sufficient to cause renal damage in the absence of invading hyphae, we measured KIM-1, a biomarker for renal proximal tubule injury in the urine of infected mice ${ }^{39,40}$. KIM-1 levels increased after infection with all strains without significant differences (Fig. 8a). Additionally, we 
a

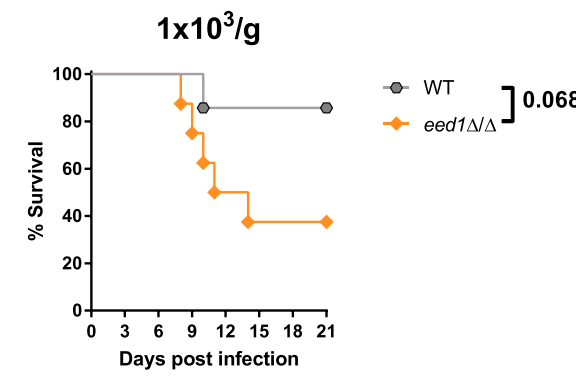

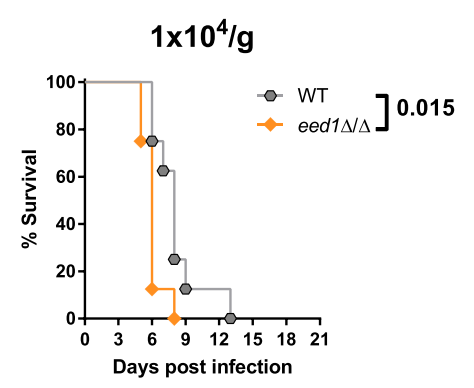

b

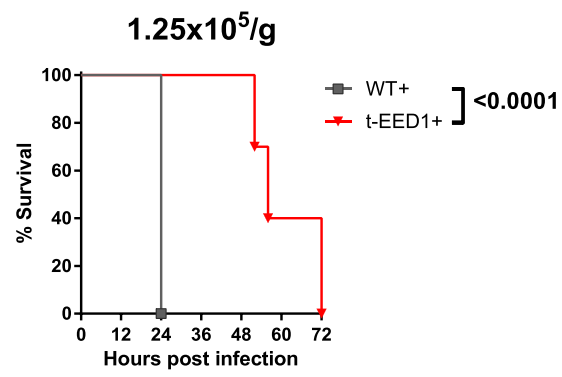

C

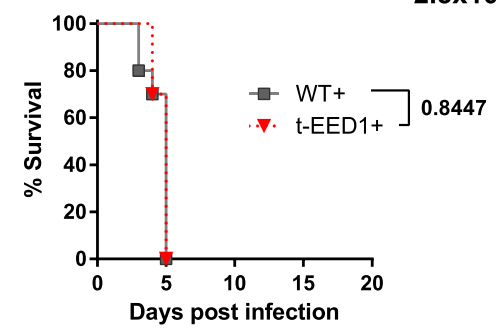

$2.5 \times 10^{4} / g$

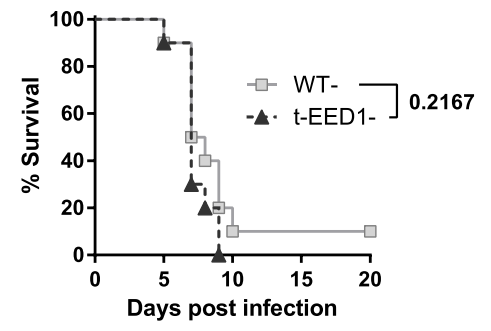

d
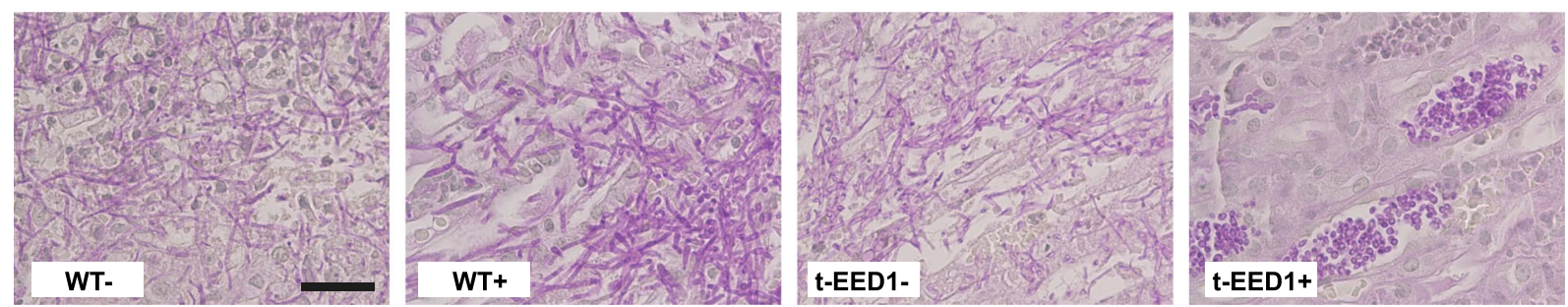

e
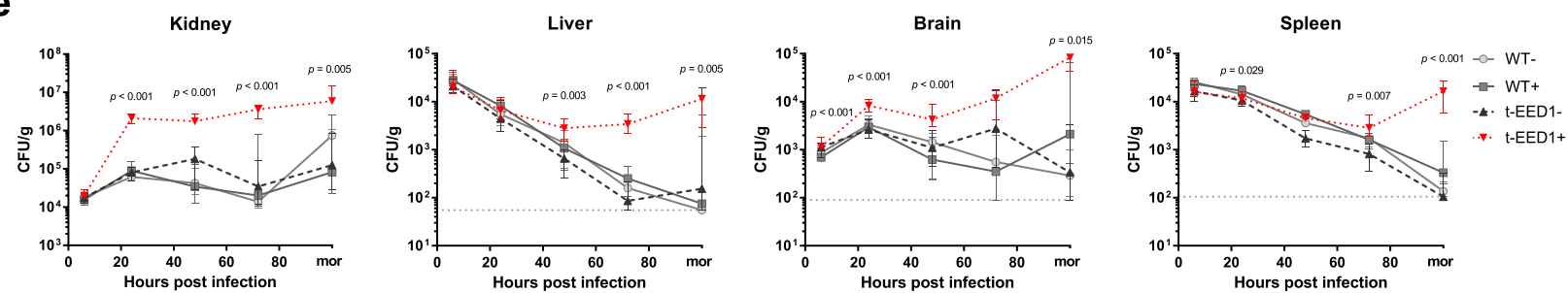

Fig. 3 C. albicans retains its virulence potential in a mouse model of systemic candidiasis even in the absence of hyphal elongation due to repression or deletion of EED1 accompanied by higher organ fungal loads. Mice were intravenously infected with the following doses: a Low doses of $1 \times 10^{3}$ or $1 \times 10^{4}$ $\mathrm{CFU} / \mathrm{g}$ body weight of WT (SC5314) or eed1 $\Delta / \Delta$ mutant. One experiment, $n=8$ mice per group (except for WT $1 \times 10^{3}, n=7$ ). b A high dose of $1.25 \times 10^{5}$ CFU/g body weight of WT (THE1-CIp10) or t-EED1 in the presence of doxycycline. One experiment, $n=10$ mice per group. c An intermediate dose of $2.5 \times$ $10^{4} \mathrm{CFU} / \mathrm{g}$ body weight with WT (THE1-CIp10) or t-EED1 in the presence $(+)$ or absence $(-)$ of doxycycline. One experiment, $n=10$ mice per group. a-c Survival was monitored over a course of 20 or 21 days and is shown as Kaplan-Meyer curve. Survival curves were compared using the two-sided Log-rank (Mantel-Cox) test, $p$-values are shown in the graph. $\mathbf{d}$ Representative images of PAS stained histological cross sections of kidneys from moribund mice infected with $2.5 \times 10^{4} \mathrm{CFU} / \mathrm{g}$ body weight with WT (THE1-CIp10) or t-EED1 in the presence $(+)$ or absence $(-)$ of doxycycline. Fungal cells are stained purple. Scale bar represents $20 \mu \mathrm{m}$ and applies to all images. e Organ fungal loads of mice infected with $2.5 \times 10^{4}$ CFU/g body weight with WT (THE1CIp10) or t-EED1 in the presence $(+)$ or absence $(-)$ of doxycycline. Shown is the number of CFU per gram organ from mice sacrificed 6, 24,48 and $72 \mathrm{~h}$ post infection and from moribund mice (mor). Data are shown as median with interquartile range. Dashed gray lines indicate limit of detection. Moribund: one experiment, $n=10$; Kidney: two independent experiments $n=10$. Liver, spleen, brain: three independent experiments, $n=15$. Two-sided Mann-Whitney test, asterisks indicate significant changes of t-EED1+ compared to WT+ groups at the indicated time points. ${ }^{\star} p \leq 0.05 ;{ }^{\star \star} p \leq 0.01$; ${ }^{\star \star \star} p \leq 0.001$. 
a
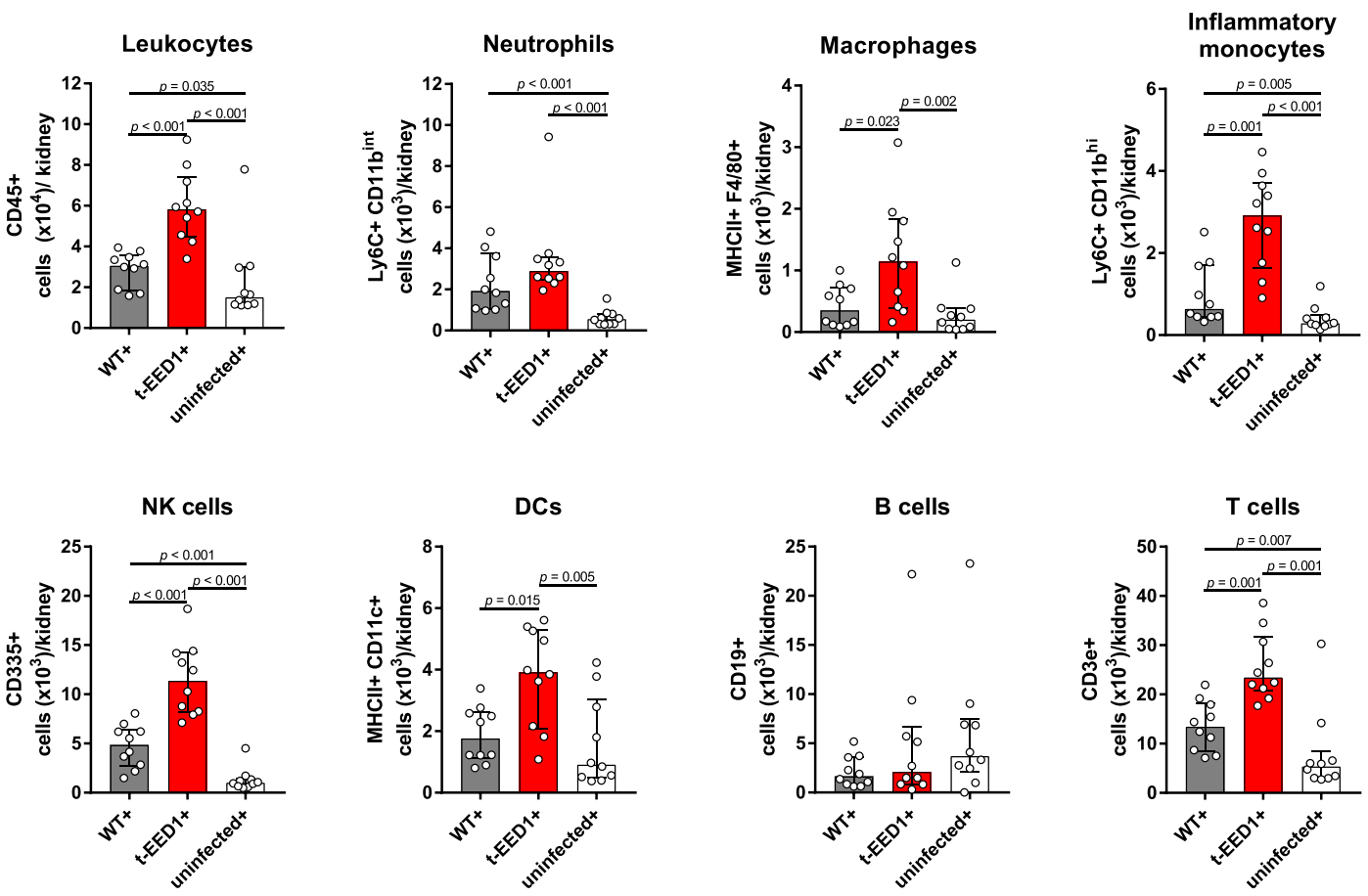

b
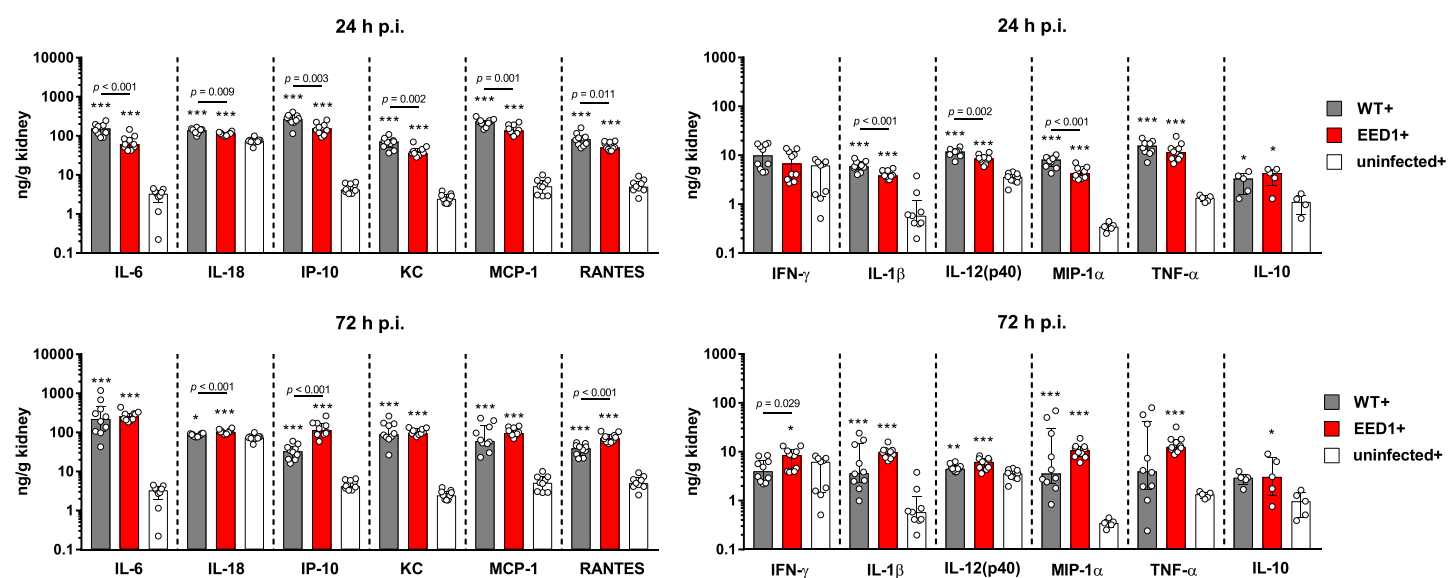

C

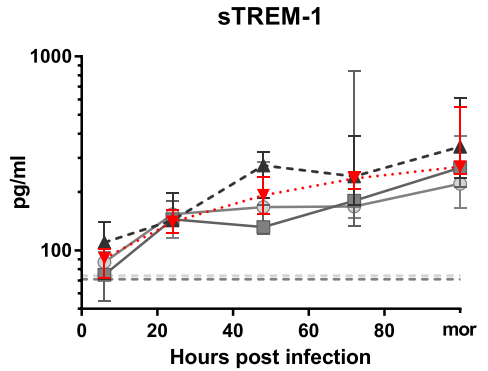

NGAL

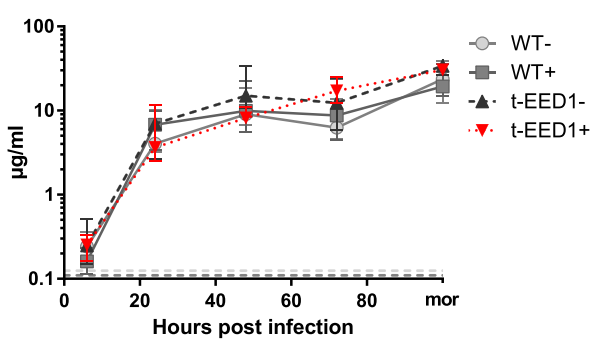

evaluated kidney function by measuring serum creatinine and blood urea nitrogen (BUN) levels. Both increased at comparable rates, reaching highly elevated levels indicating severe renal dysfunction $^{41,42}$ in moribund mice only (Fig. 8b, c). Finally, the same extent of apoptosis was observed in the kidneys of moribund mice infected with either WT or t-EED1 (Fig. 8d, e). Therefore, enhanced fungal proliferation can compensate for the reduced capacity of hypha-mediated damage in C. albicans lacking expression of EED1.

Rapid yeast proliferation in combination with immunopathology contributes to mortality. To investigate whether mortality caused by the yeast form is the result of high organ fungal loads interfering with organ function or whether 
Fig. 4 Increased immune cell infiltration in kidneys of mice $72 \mathrm{~h}$ after systemic infection with t-EED1+ yeast coincides with increased local cytokine production while systemic inflammation is not affected. Mice were systemically infected with an intermediate dose of $2.5 \times 10^{4} \mathrm{CFU} / \mathrm{g}$ body weight of WT (THE1-CIp10), t-EED1 or remained uninfected in the presence $(+)$ of doxycycline. a Immune cells infiltrating the kidney $72 \mathrm{~h}$ post infection. Shown are absolute numbers of living immune cells per kidney. Two independent experiments, $n=10$. $\mathbf{b}$ Cytokine levels were measured in kidney homogenates $24 \mathrm{~h}$ and $72 \mathrm{~h}$ post infection. Asterisks above bars represent significant differences compared to the uninfected control. Two independent experiments, $n=10$, except for uninfected,$+ n=9$. MIP- $1 \alpha$, TNF- $\alpha$ for uninfected,$+ n=5$. IL-10 data derived from one experiment, $n=5$. c Markers for systemic inflammation STREM- 1 and NGAL were quantified by ELISA in serum of mice after $6,24,48,72 \mathrm{~h}$ and when mice become moribund (mor). Dashed lines indicate median serum protein levels of uninfected controls in the presence (dark gray) or absence of doxycycline (light gray). Two independent experiments. sTREM- $n=$ 10, except for $6 \mathrm{~h} n=6$ and mor $n=5$; for WT- $24 \mathrm{~h} n=8$ and $48 \mathrm{~h} n=9$. NGAL $n=10$, except for WT $-24 \mathrm{~h} n=9$, t-EED1- $24 \mathrm{~h} n=8$ and $72 \mathrm{~h} n=9$. a-c Shown is the median and interquartile range, two-sided Mann-Whitney test. $\mathbf{a}, \mathbf{b} p$-values are shown in the graph and $\mathbf{b}$ asterisks indicate significant differences in comparison to the uninfected control $\left.{ }^{\star} p \leq 0.05 ;{ }^{\star \star} p \leq 0.01 ;{ }^{\star \star \star} p \leq 0.001\right)$. Source data are provided as a Source Data file.

immunopathology is the driving force in the pathogenic process, mice successfully depleted of peripheral neutrophils and monocytes (Supplementary Fig. 17) were intravenously infected with low infectious doses $\left(1 \times 10^{2}\right.$ and $1 \times 10^{3} \mathrm{CFU} / \mathrm{g}$ body weight $)$. Although the eed $1 \Delta / \Delta$ mutant led to $100 \%$ mortality in immunosuppressed mice, this was significantly delayed in comparison to WT strain infections (Fig. 9a). However, in immunocompetent mice challenged with $1 \times 10^{3} \mathrm{CFU} / \mathrm{g}$ body weight, the obverse effect was observed: while $6 / 7$ mice survived in the WT, only $3 / 8$ mice survived in the eed $1 \Delta / \Delta$ group until the end of the experiment (Fig. 3a). In addition, histological analysis of renal tissue showed more pronounced immune cell infiltrations in response to eed $1 \Delta / \Delta$ yeast in immunocompetent mice (Fig. 9b), suggesting some contribution of immunopathology to yeast driven mortality. In the absence of neutrophils and monocytes, fungal burden of WT and eed $1 \Delta / \Delta$ mutant progressively increased during the course of infection. However, organ fungal load of the eed $1 \Delta / \Delta$ mutant exceeded that of the WT in all organs tested, with significant differences detectable as early as $12 \mathrm{~h}$ post infections in liver and kidneys (Fig. 9c). At the humane endpoint, the fungal burden of the eed $1 \Delta / \Delta$ mutant exceeded those of the WT in all organs tested (Fig. 9c and Supplementary Fig. 18a) with a 150fold and 280-fold increase in kidney and spleen fungal burden, respectively. Furthermore, the urinary KIM-1 to creatinine ratio steadily increased after infection with $C$. albicans eed $1 \Delta / \Delta$, indicating that filaments are not essential for induction of renal injury (Fig. 9d). However, kidney function as determined by measurement of BUN in serum of immunosuppressed mice was not affected at any time after infection with WT or eed $1 \Delta / \Delta$ mutant (Supplementary Fig. 18b), possibly because the time to the humane endpoint was too short to allow accumulation of waste products by impaired renal clearance.

\section{Discussion}

C. albicans hypha formation has been linked to invasion and damage, and C. albicans strains locked in either the yeast or hyphal morphology were repeatedly found to be less virulent in systemic infection models ${ }^{15-18}$. Consequently, morphological plasticity is considered as an important virulence trait of $C$. albicans ${ }^{43,44}$. Consistent with the role of filamentation for invasion and damage, repression or absence of EED1 in C. albicans, interfering with hyphal elongation and leading to yeast growth, resulted in significantly reduced capacity to damage epithelial cells in vitro, and reduced virulence in a murine intraperitoneal infection model in vivo although the mutant was present in higher numbers than the WT in the liver. The observation that following intraperitoneal injection EED1-deficient cells superficially invaded the liver parenchyma but remained below the liver capsule, without causing detectable damage, resembles the described behavior of the eed $1 \Delta / \Delta$ mutant in a reconstituted human epithelium model ${ }^{20}$. Thus, our results support previous research demonstrating that hyphae are important for tissue infiltration. In the gut, however, C. albicans can be found in both yeast and hyphal form ${ }^{28,45,46}$. Some studies found higher colonization rates for strains locked in the yeast morphology (e.g., the $\operatorname{cph} 1 \Delta / \Delta$ efg $1 \Delta / \Delta$ double mutant and the $h g c 1 \Delta / \Delta$ mutant $^{28}$ ), whereas enforced filamentous growth resulted in lower intestinal colonization (e.g. C. albicans $n r g 1 \Delta / \Delta$ and $t u p 1 \Delta / \Delta$ mutants ${ }^{27,28}$, repression of TUP1 $1^{29}$, and constitutive expression of $U M E 6^{28,45}$ ). We likewise observed higher colonization rates for the eed $1 \Delta / \Delta$ mutant in immunocompetent mice, supporting the concept that yeast growth favors intestinal colonization. How C. albicans is translocating across the intestinal barrier remains unknown. In vitro, translocation requires filamentation ${ }^{22}$, but low level translocation has been observed in immunocompetent mice independent of fungal morphology ${ }^{28}$. This has been suggested to be mediated by transport via host cells that sample the intestinal content $^{28}$. We observed reduced basal dissemination of the eed $1 \Delta / \Delta$ mutant to the liver, which might be a consequence of altered interaction of the mutant with dendritic cells or $\mathrm{M}$ cells mediating entry into the bloodstream by lumen sampling or transcytosis ${ }^{28,47}$ in the absence of hyphal formation, but this aspect was not investigated further in this study. In contrast, increased fungal burden in liver and kidney was observed in $C$. albicans eed $1 \Delta / \Delta$ colonized mice treated with cyclophosphamide, and in these mice kidney CFU were significantly higher for the eed $1 \Delta / \Delta$ compared to the WT. However, this data does not allow any conclusion on the translocation process, as the higher fungal load could also be a consequence of increased proliferation of the mutant within this organ. It should furthermore be noted that the fungal burden in kidneys following translocation from the gut was substantially lower than that observed after intravenous infection, which explains why colonized mice did not develop signs of systemic candidiasis upon cyclophosphamide treatment.

Surprisingly, the filamentation defect caused by EED1 deficiency did not impair virulence in a systemic infection model when intermediate infectious doses were injected directly into the bloodstream. Remarkably, infectious doses lower than $10^{4}$ cells per gram body weight resulted in increased virulence of the eed $1 \Delta / \Delta$ mutant compared to the WT, whereas with high infectious doses or in absence of neutrophils and monocytes mortality was delayed but still reached $100 \%$. In the murine model of hematogenously disseminated candidiasis, infection is established via the lateral tail vein mimicking disseminated $C$. albicans infections in humans ${ }^{48}$. While virtually all organs can get affected during infection the kidney is not able to control fungal growth ${ }^{49}$. The fungus reaches the kidneys via the renal artery and the afferent arterioles. In order to invade into tubules and the renal parenchyma, the fungus needs to adhere to endothelial cells and pass through into the renal cortex. This step probably does not require fungal invasion by hypha formation, as tet-NRG1- yeast and a $h g c 1 \Delta / \Delta$ mutant defective in hyphal formation were shown to traverse from the bloodstream to the renal endothelium ${ }^{14,16}$. Although attenuated in its damage capacity, the eed $1 \Delta / \Delta$ mutant 
a

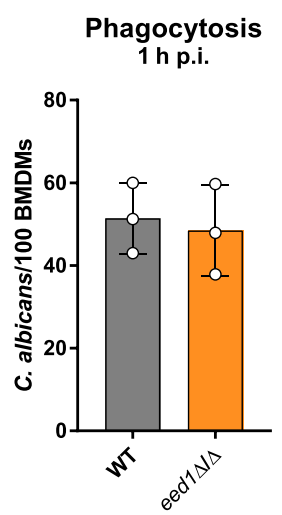

d

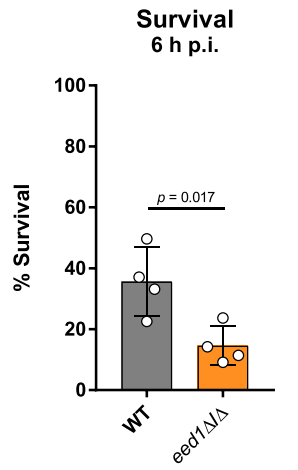

b

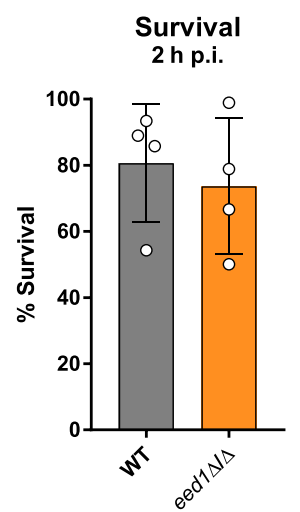

$\triangle \mathrm{CFU}$

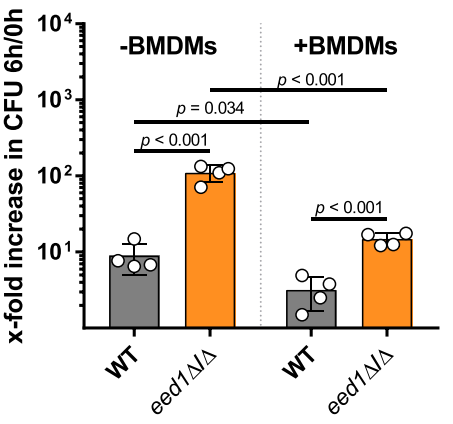

C

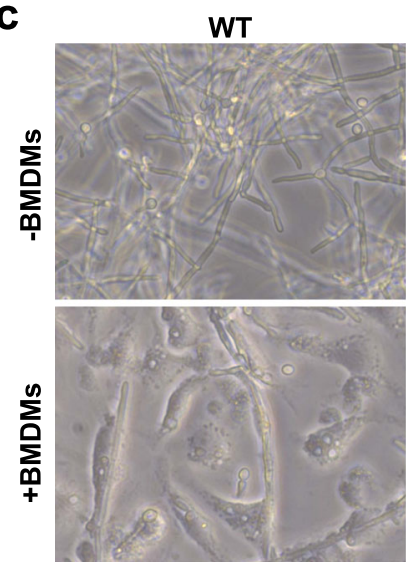

e

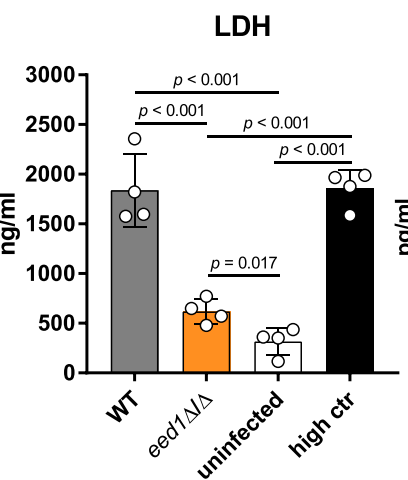

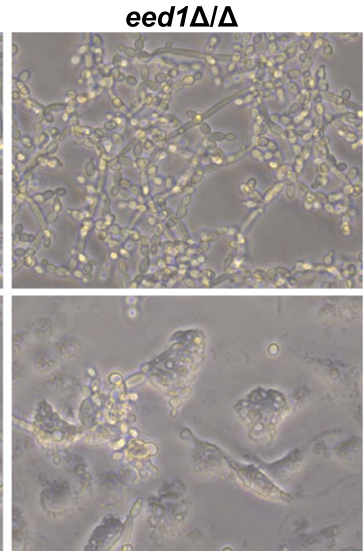

f

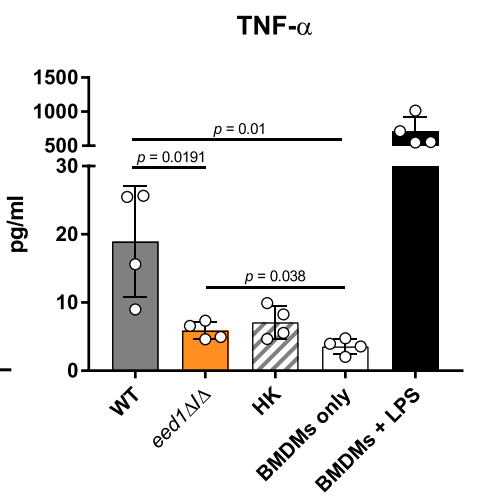

g

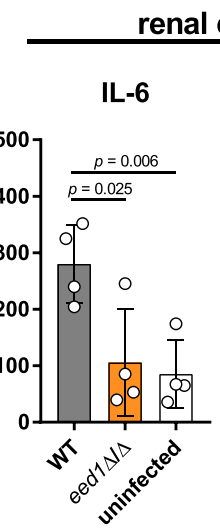

enal cells (A498)

IL-8

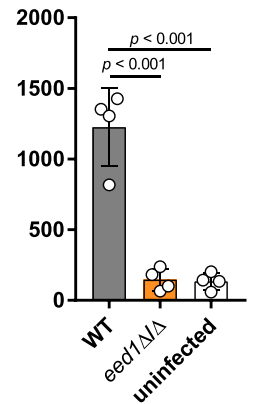

hepatic cells (HepaRG)

IL-6

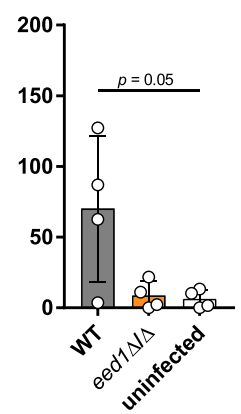

IL-8

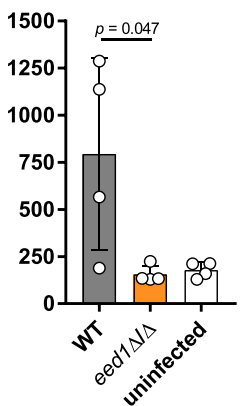

oral cells (TR146)

IL-6

IL-8

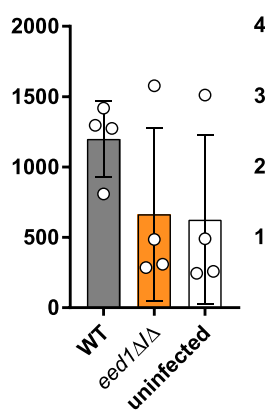

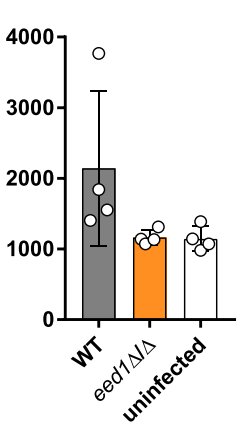

Fig. 5 eed1 $\Delta / \Delta$ yeast are less efficient in damaging and inducing cytokine responses of bone marrow-derived macrophages (BMDMs) and epithelial cells. Murine bone marrow-derived macrophages (BMDMs) were infected at an MOI of 1 with C. albicans WT (SC5314) or eed1 $\Delta / \Delta$ mutant and incubated at $37{ }^{\circ} \mathrm{C}$ and $5 \% \mathrm{CO}_{2}$. a Phagocytosis calculated as phagocytic index (the number of $\mathrm{C}$. albicans cells phagocytosed by 100 BMDMs within $1 \mathrm{~h}$ of incubation). Mean \pm SD from three biologically independent experiments. b Fungal survival was analyzed after co-incubation with BMDMs for $2 \mathrm{~h}$ by $\mathrm{CFU}$ plating. Survival was normalized to $C$. albicans controls incubated in the absence of immune cells. c Fungal morphology of WT and eed $1 \Delta / \Delta$ mutant in the absence $(-)$ or presence $(+)$ of BMDMs after $6 \mathrm{~h}$ of incubation. Scale bar represents $20 \mu \mathrm{m}$ and applies to all images. $\mathbf{d}$ Fungal survival was analyzed after co-incubation with BMDMs for $6 \mathrm{~h}$ by CFU plating. Left: Survival was normalized to C. albicans controls incubated in the absence of immune cells. Right: To account for the observation that the mutant replicates faster than the WT in the absence of macrophages, data is shown as fold increase in CFU from $0 \mathrm{~h}$ to $6 \mathrm{~h}$ with and without BMDMs. e Damage of BMDMs was quantified by measuring lactate dehydrogenase (LDH) release into the supernatant after $24 \mathrm{~h}$ of co-incubation with $C$. albicans WT or eed1 $\Delta / \Delta$ mutant. Uninfected cells served as negative control and Triton X-100 lysed cells served as high control. f TNF- $\alpha$ release of BMDMs $24 \mathrm{~h}$ after co-incubation with C. albicans WT (SC5314), eed1 $\Delta / \Delta$ mutant or heat-killed (HK) WT cells. BMDMs were left untreated (BMDM only) or stimulated with $100 \mathrm{ng} / \mathrm{ml}$ LPS as positive control. $\mathbf{g}$ Release of IL-6 and IL-8 by renal (A498), hepatic (HepaRG) and oral (TR146) epithelial cells $24 \mathrm{~h}$ after infection with C. albicans. Uninfected cells served as negative control. b, d, e, $\mathbf{f}, \mathbf{g}$ Mean \pm SD of four biologically independent experiments are shown. $\mathbf{b}, \mathbf{d}$ In each experiment, three wells were infected with each strain and fungal survival was quantified per well. The mean of these three samples is shown as single point for the individual experiment. Data were analyzed by two-tailed student's $t$-test. $p$-values are shown in the graph. Source data are provided as a Source Data file. 

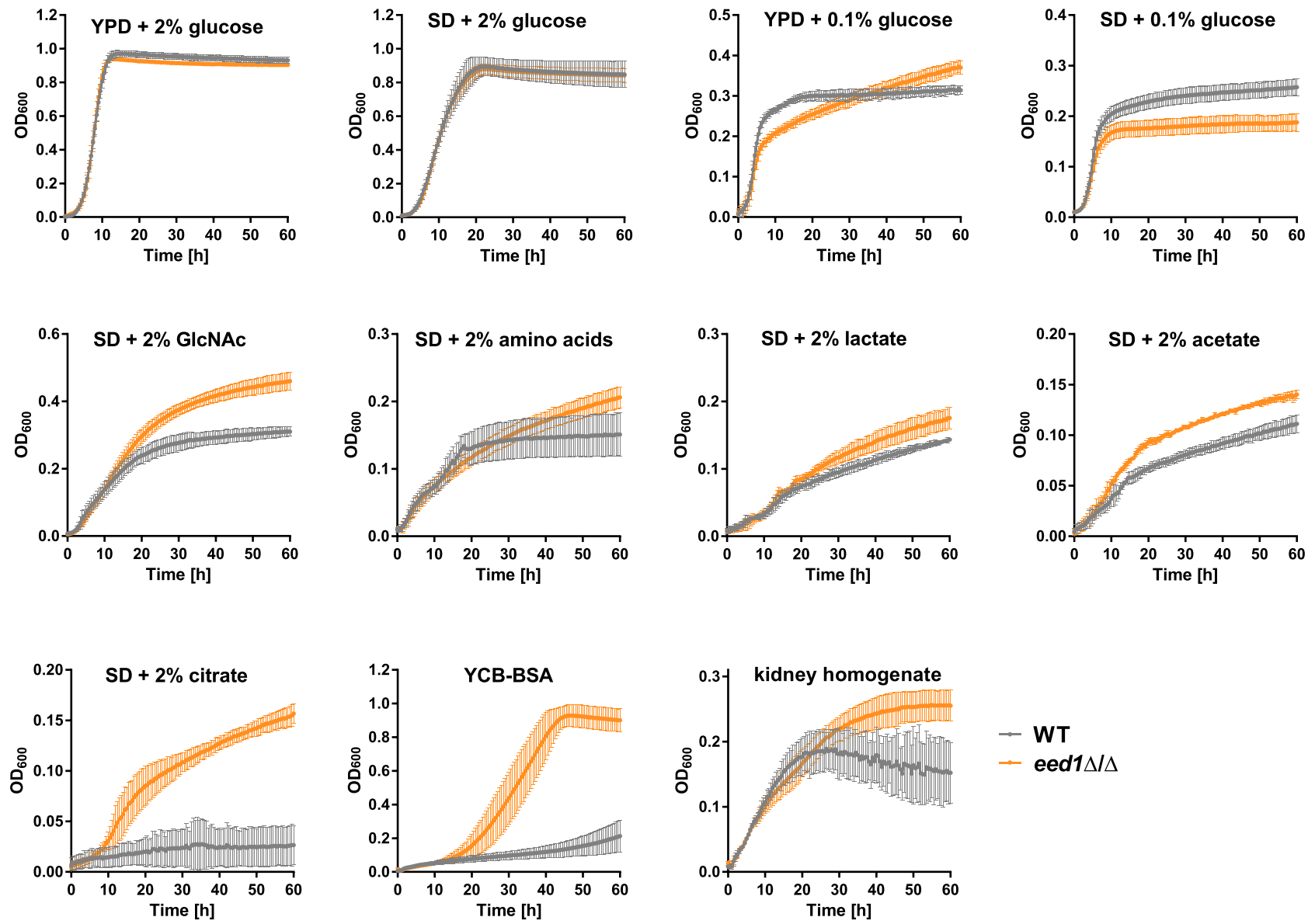

Fig. 6 eed1 $\Delta / \Delta$ yeast have a growth advantage on physiologically relevant carbon sources and kidney homogenates and furthermore show enhanced proteolytic activity. Growth curves of C. albicans in YPD with 2 or $0.1 \%$ glucose or SD medium with different concentrations of sugars or alternative carbon sources as indicated in the graphs. YCB-BSA contained $0.5 \%$ of BSA as sole nitrogen source, pH was adjusted to 4.0. For kidney homogenates, kidneys of uninfected mice were removed aseptically, homogenized and diluted to $25 \mathrm{mg} / \mathrm{ml}$ in DPBS. Growth was recorded by measuring the optical density at 600 $\mathrm{nm}$ in a microplate reader at $37^{\circ} \mathrm{C}$. Measurements were performed in 30 min intervals over a course of $60 \mathrm{~h}$. Graphs show the mean \pm SD of three to five independent biological replicates. Source data are provided as a Source Data file.

is able to adhere and invade into epithelial cells in vitro ${ }^{20,50}$, which might be sufficient to mediate entry into renal tissue in vivo. Thus, while filamentation is required for active tissue penetration in the intraperitoneal infection model, it might be dispensable if defensive barriers are breached by direct injection into the blood stream.

Following establishment of the fungus in the kidney in immunocompetent mice, pathogenesis is thought to be driven by both direct fungus-mediated damage and immunopathology. Enhanced immunopathology could compensate for the lack of hypha-mediated fungal damage during pathogenesis; however, in the early time points following infection with an intermediate infectious dose of t-EED1+ yeast we rather observed a reduced induction of pro-inflammatory cytokines, likely as a result of the reduced capacity of the yeast to directly damage epithelial cells and macrophages and stimulate cytokine release. Macrophages have been shown to be less prone to killing by hypha-deficient strains $^{51}$ and to release less TNF- $\alpha$ after stimulation with $C$. albicans strains unable to germinate; 52 likewise, murine macrophages produced less TNF- $\alpha$ in response to the eed $1 \Delta / \Delta$ mutant. However, the amount of TNF- $\alpha$ in infected kidneys was not affected by absence of EED1-driven filamentation and the interaction with murine neutrophils in vitro was comparable for WT and eed $1 \Delta / \Delta$ mutant. Interestingly, while killing of the mutant by BMDMs was increased after $6 \mathrm{~h}$ of co-incubation, the relative increase in CFU was higher for the eed $1 \Delta / \Delta$ mutant than for the WT, suggesting that the increased proliferation is sufficient to compensate for the higher killing rate mediating survival and allowing for continuous organ colonization. It thus appears unlikely that the higher renal fungal burden of the yeast is solely due to reduced fungal clearance as a result of impaired recognition by and/or activation of immune cells.

We hypothesized that increased fitness mediated by better metabolic adaptation to the locally available nutrients facilitated rapid proliferation of EED1 deficient yeast in vivo in the systemic infection model, and that the higher fungal burden in the liver after intraperitoneal infection might likewise reflect increased growth of the mutant. Upon infection C. albicans faces a hostile environment with varying nutritional compositions. Preferred carbon sources such as glucose are present only in low concentrations in the bloodstream $\left(0.06-0.1 \%{ }^{53}\right.$,) and can become scarce in microenvironments or deprived by phagocytes upon ingestion ${ }^{10}$. Consequently, C. albicans relies on the assimilation of alternative carbon sources in order to survive and proliferate within the host ${ }^{54}$. As Crabtree-negative yeast, C. albicans is able to assimilate glucose and alternative carbon sources such as amino acids, fatty acids, and carboxylic acids, at the same time ${ }^{55}$. This metabolic flexibility is known to increase colonization, resistance to phagocytic recognition ${ }^{56}$ and killing, and enhances pathogenicity 57,58 . The eed $1 \Delta / \Delta$ mutant indeed showed enhanced 
a
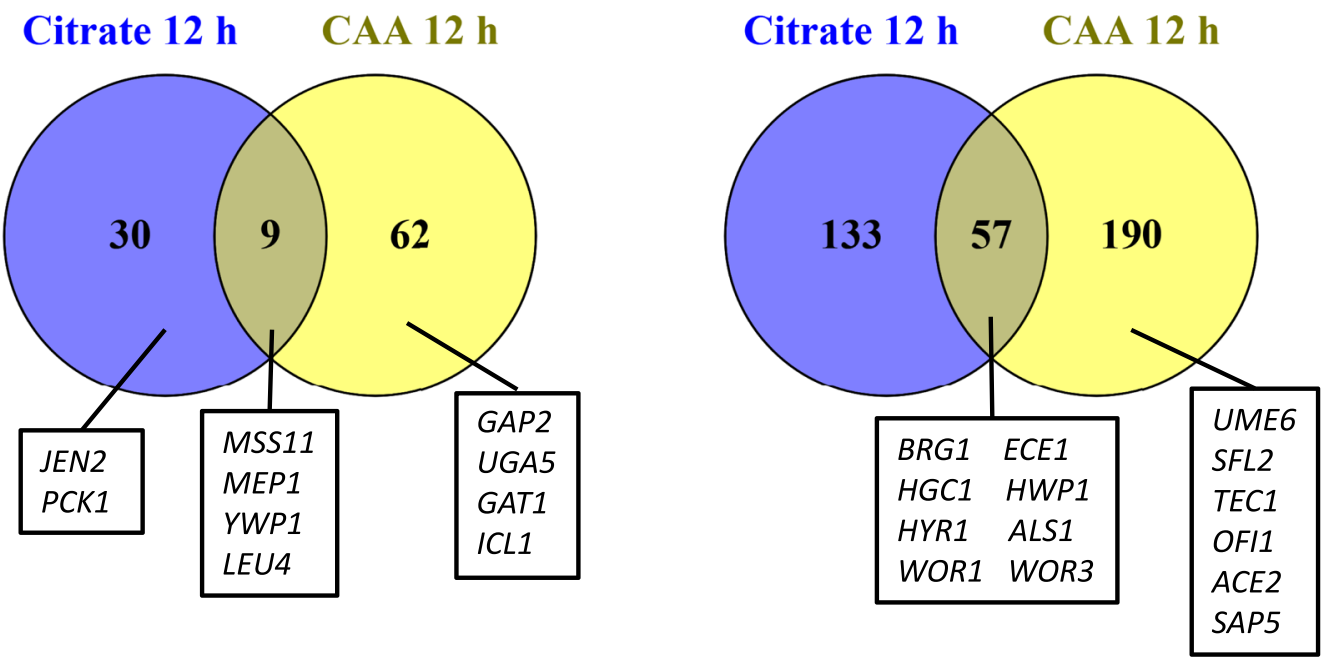

b
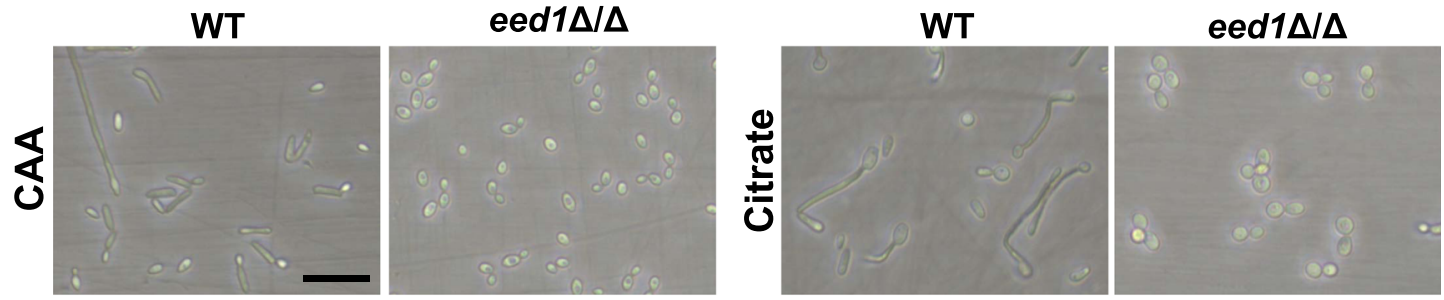

C
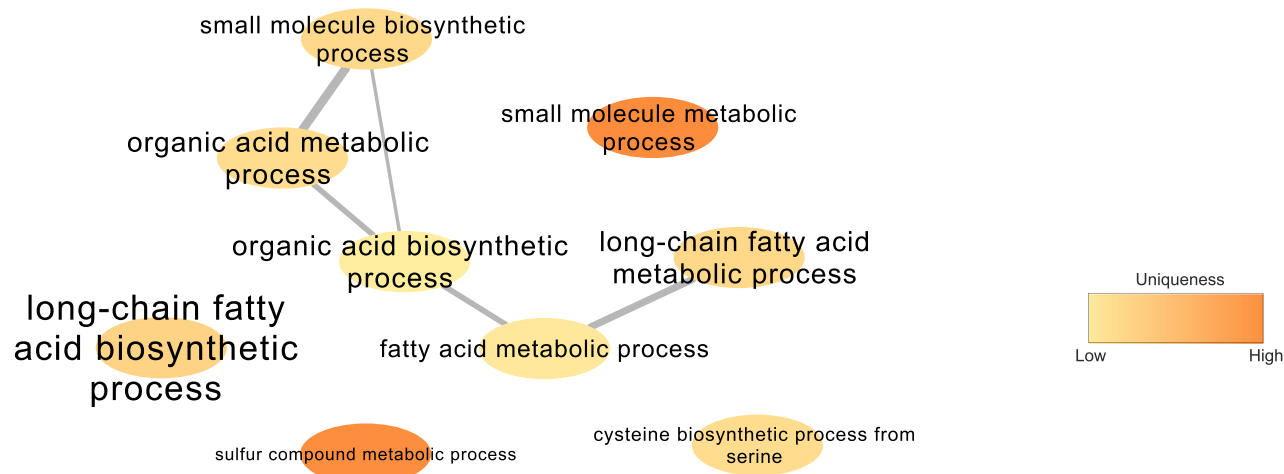

cysteine biosynthetic process from serine

Fig. 7 Transcriptional analysis of the eed1 $\Delta / \Delta$ mutant during growth on citrate or casamino acids (CAA) after $12 \mathrm{~h}$ at $37^{\circ} \mathrm{C}$. a $V e n n$ diagrams showing the numbers of genes significantly up- or down-regulated $\left( \pm \log _{2} 2\right.$ and adjusted $p$-value $<0.05$ ) in the eed1 $\Delta / \Delta$ mutant compared to WT (SC5314) with citrate or CAA as sole carbon source. Genes referred to in the text are highlighted. b Morphology of C. albicans WT and eed1 $\Delta / \Delta$ mutant after $12 \mathrm{~h}$ of growth on citrate or CAA. Representative pictures from three biologically independent experiments are shown. Scale bar represents $20 \mu \mathrm{m}$ and applies to all images. c Network analysis of Gene Ontology (GO) term enrichments of significantly up-regulated genes ( $+\log _{2} 2$ and adjusted $p$-value $<0.05$ ) in eed $1 \Delta / \Delta$ mutant compared to WT after $12 \mathrm{~h}$ of growth on citrate. Font size represents the $p$-value $(p<0.1)$ of the GO term: big letters - small $p$ value, ranging from $p<2.3 \times 10^{-5}$ to low $p$-value $p<0.09$ indicated by small letters. Color is representing the uniqueness, indicating how particular each term is with respect to the set of terms being evaluated (original data analyzed are available in Supplementary Data 1).

growth in kidney homogenates and in the presence of alternative carbon sources that are available in vivo, such as acetate, lactate, amino acids, citrate, and the amino sugar $\mathrm{N}$-acetyl-glucosamine. Additionally, the eed $1 \Delta / \Delta$ mutant displayed an enhanced proteolytic activity, possibly supporting utilization of host proteins and immune evasion by degradation of complement proteins and antimicrobial peptides in vivo ${ }^{59-61}$. Whereas hypha-associated $S A P s$ appeared to be down-regulated during growth on casamino acids, enhanced expression of SAP1, SAP3, SAP7, SAP9 and
SAP10 was observed. Since Sap1-3, Sap4-6 and Sap9-10 have different $\mathrm{pH}$ optima for activity, $\mathrm{pH} \mathrm{3-5,} \mathrm{pH} \mathrm{5-7}$ and $\mathrm{pH} 5-8$, respectively, and in addition Saps differ in their substrate specificity ${ }^{31,62}$, this compensatory gene expression might lead to the earlier onset of BSA utilization observed for the eed $1 \Delta / \Delta$ mutant. The increased growth on citrate is especially interesting as citrate is present in blood in a range of 0.05 to $0.3 \mathrm{mM}$, freely filtered in the glomerulus, and extensively reabsorbed in the nephrons of the kidney ${ }^{63}$. Therefore, citrate levels are 
a

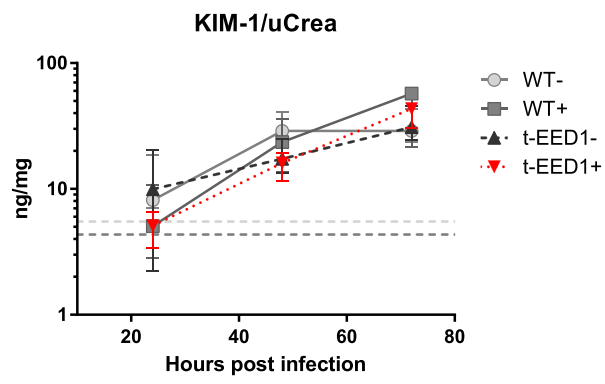

b

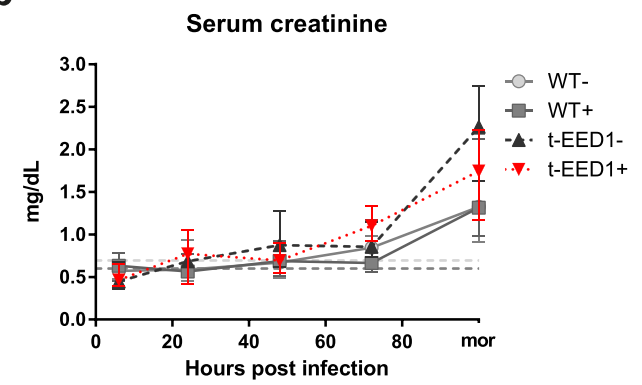

C

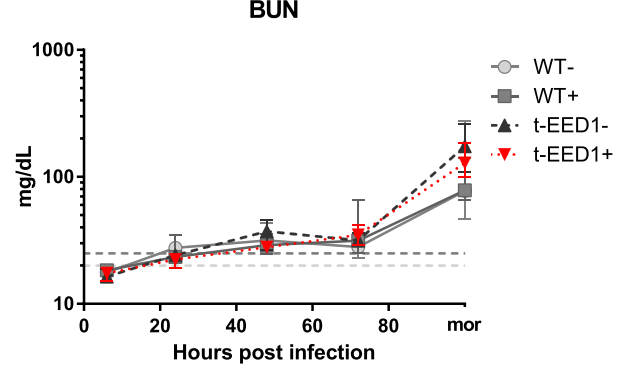

d
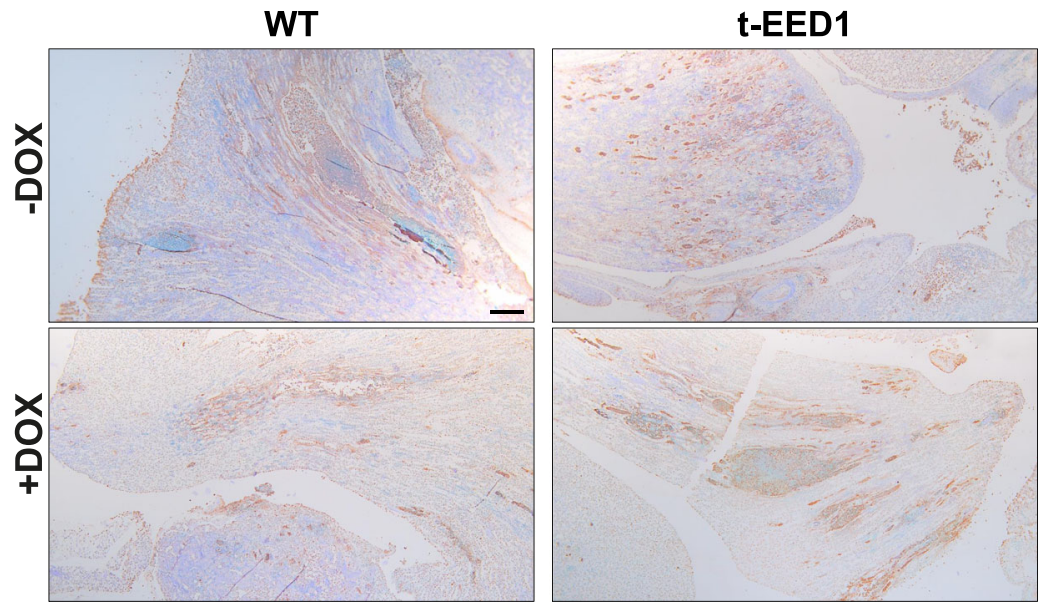

e

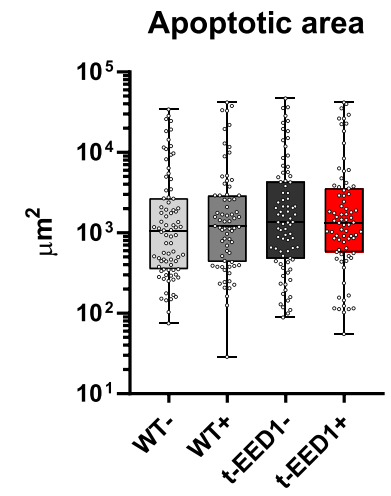

Fig. 8 Kidneys are injured early after intravenous challenge with C. albicans by yeast and hyphal forms, while kidney function is not impaired within 72 $h$ post infection. When moribund, mice developed severe renal dysfunction accompanied by renal apoptosis. a Kidney injury was quantified by measuring and normalizing urinary KIM-1 level to urinary creatinine 24,48 and $72 \mathrm{~h}$ post infection. Two independent experiments, $n=10$ per group except for WT- 24 and $48 \mathrm{~h}$ and t-EED1 $+72 \mathrm{~h}: n=9$. Biomarkers for kidney function $\mathbf{b}$ serum creatinine and $\mathbf{c}$ blood urea nitrogen (BUN) were quantified in serum of mice $6,24,48,72 \mathrm{~h}$ post infection and increased especially in serum of moribund (mor) mice. Two independent experiments. Serum creatinine $n$ $=10$, except for WT- mor, WT+ 24-72 h, t-EED1+ 24 and $48 \mathrm{~h} n=9$, for t-EED1- $6 \mathrm{~h}$ and t-EED1+ mor $n=8$. BUN $n=10$, except for WT- 24, 48 h and mor $n=9, t-E E D 1+$ mor $n=8$. a-c Dashed lines indicate median serum biomarker level of uninfected controls in the presence $(+$, dark gray) or absence of doxycycline (-, light gray). Data are shown as median and interquartile range. $\mathbf{d}$ Immunohistochemistry of the renal pelvis of moribund mice identified apoptotic areas stained in brown. Scale bar represents $200 \mu \mathrm{m}$. e Quantification of apoptotic areas in kidneys of moribund mice ( $n=5$ per group). Shown are apoptotic areas in $\mu \mathrm{m}$ in box-and-whiskers graph with min to max. No significant changes were observed by two-sided Mann-Whitney test. Source data are provided as a Source Data file.

approximately 3-4-fold higher in the renal cortex than in plasma. Furthermore, mice develop metabolic alkalosis early after systemic infection ${ }^{48}$ which is known to further increase citrate concentration in the cortex, and in addition enhances renal citrate excretion 20 -fold compared to the steady state ${ }^{63}$. Therefore, citrate could be an abundant source of carbon available for $C$. albicans in the renal cortex and tubules during the early phase of systemic infection. Thus, enhanced growth on citrate might contribute to the higher renal fungal burden in the absence of EED1 expression. Transcriptional profiling during growth of $C$. albicans on citrate as sole carbon source revealed only few genes that were up-regulated in the eed $1 \Delta / \Delta$ mutant compared to the WT after $12 \mathrm{~h}$. These, however, included genes involved in metabolism of carboxylic acids and hence could aid in the metabolism of citrate. Similarly, upregulation of GAT1 might be promoting growth on casamino acids. However, many metabolic enzymes are regulated by posttranscriptional modifications to respond quickly to changing environmental conditions ${ }^{64,65}$, and it is therefore likely that the transcriptional changes described here reflect only in part the 
a

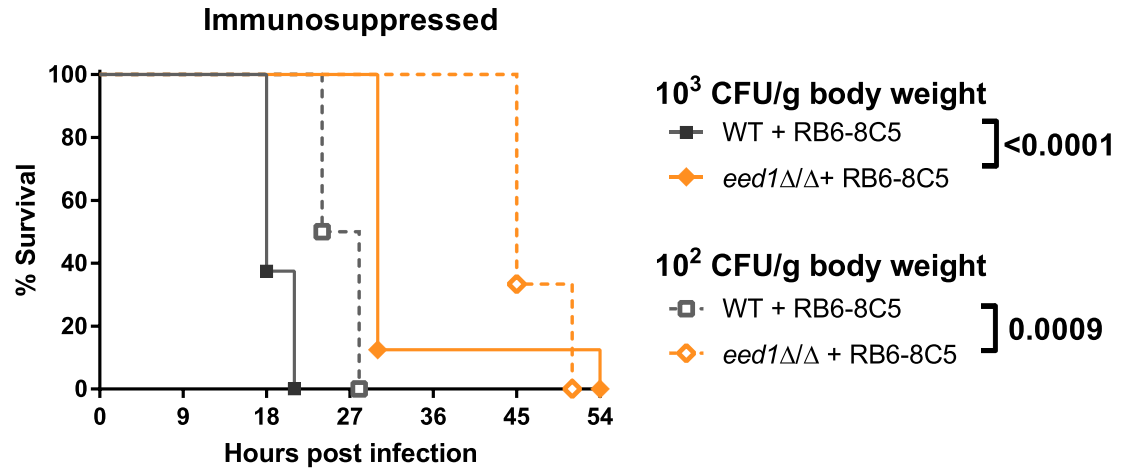

b
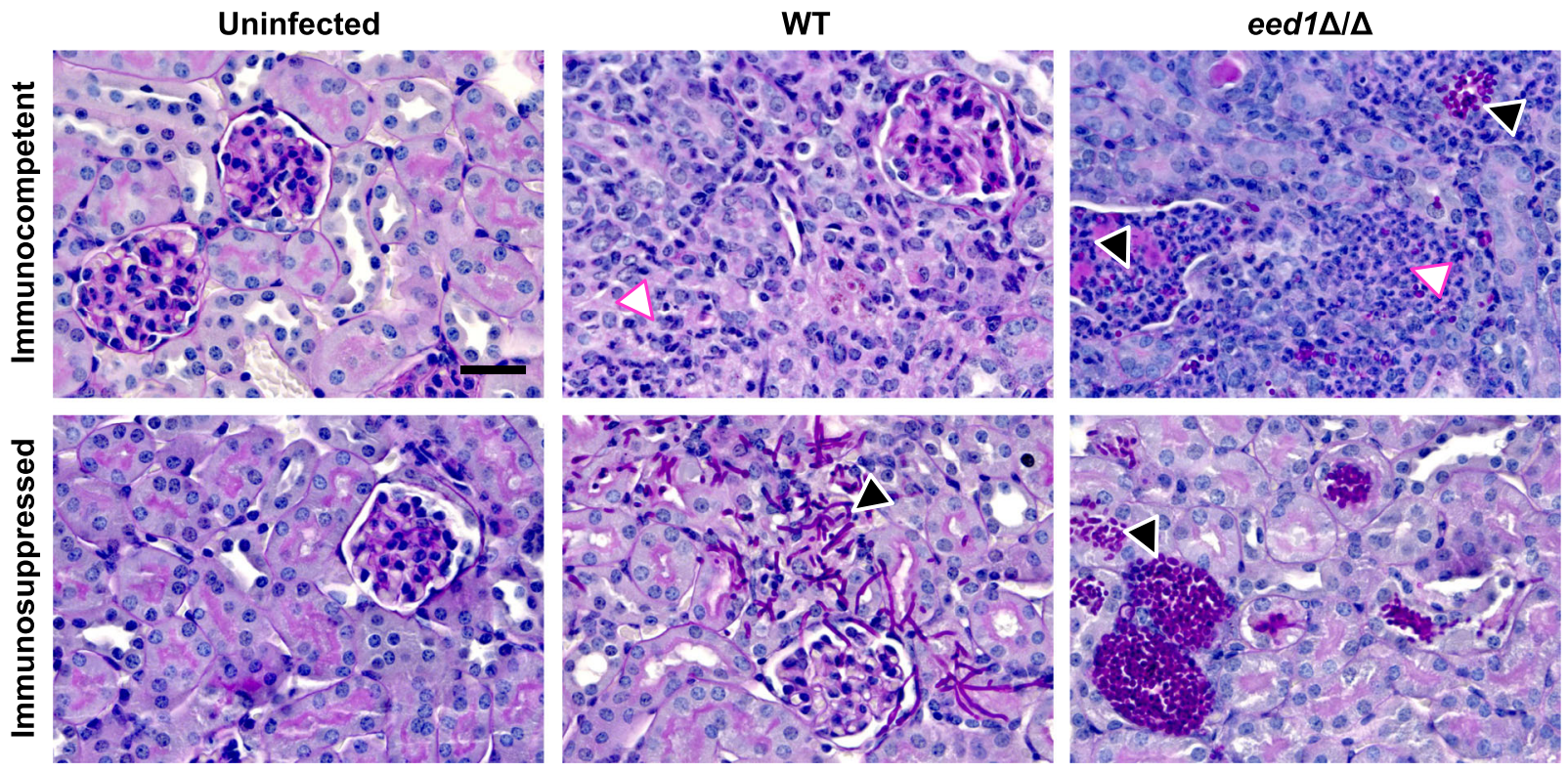

C
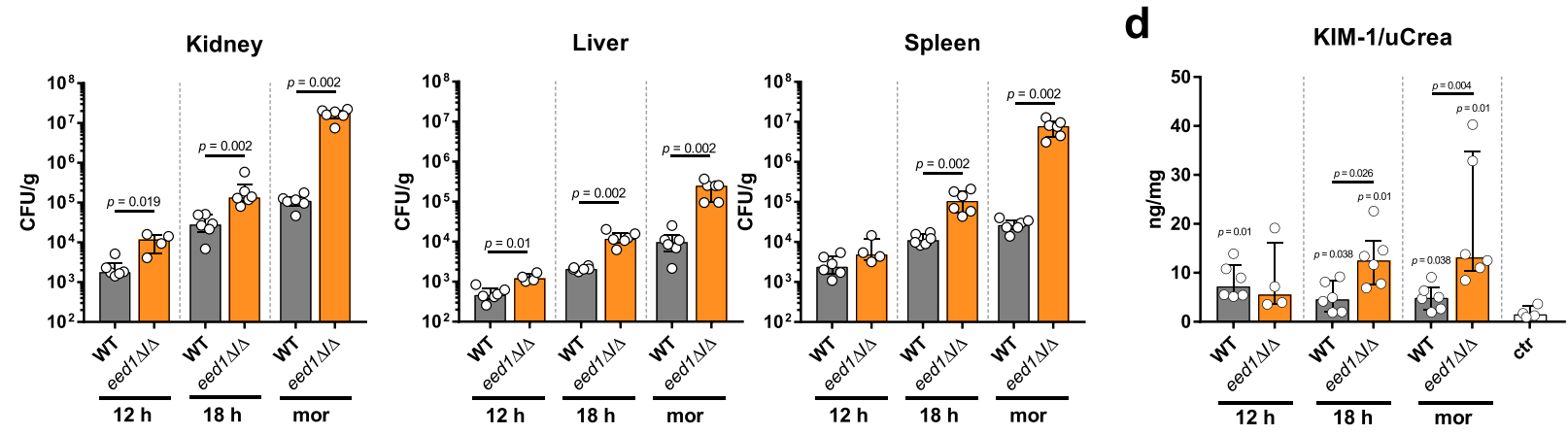

cellular changes leading to enhanced proliferation of the eed $1 \Delta /$ $\Delta$ mutant.

Infection with t-EED1+ yeast resulted in higher organ fungal burden, significantly more leukocytes infiltrating the kidneys and increased renal pro-inflammatory cytokine production at later time points contributing to local immunopathology ${ }^{49,66}$. Markers of systemic inflammation, sTREM-1 and NGAL, increased rapidly in serum of infected mice irrespective of fungal morphology. NGAL thresholds defining sepsis in humans ${ }^{67}$ and sTREM-1 thresholds in mice ${ }^{68}$ were reached within $24 \mathrm{~h}$ after infection, while damage of proximal tubular cells measured by KIM-1 became detectable slightly later (between 24 and 48 h p.i.).

Impaired kidney function determined by increased blood urea nitrogen level and serum creatinine was only evident in moribund mice, consistent with findings by Spellberg et al. ${ }^{48}$, again without significant differences between hypha-forming and filamentdeficient strains. Histologically, t-EED1+ yeast were found in large numbers mainly within tubules and in the renal pelvis; it appears possible that accumulation of yeast led to obstruction of tubules and the collecting duct system ${ }^{69}$, increasing the intrarenal pressure and thereby, in addition to immunopathology, causes renal tissue damage. This is supported by our data showing that the area of apoptotic tissue in kidneys did not differ between mice infected with WT and t-EED1+ and suggests that the lack of 
Fig. 9 Systemic infection with the $C$. albicans eed1 $\Delta / \Delta$ mutant leads to delayed mortality of immunosuppressed mice despite higher fungal burden accompanied by increased kidney injury compared to mice infected with the WT. Mice that were rendered immunosuppressed by depletion of neutrophils and monocytes using the RB6-8C5 antibody were intravenously infected with $1 \times 10^{2}, 1 \times 10^{3}$ or $1 \times 10^{4}$ CFU/g body weight of C. albicans WT (SC5314) or eed1 $\Delta / \Delta$ mutant. a Survival of mice was monitored after infection with $1 \times 10^{2} \mathrm{CFU} / \mathrm{g}$ or $1 \times 10^{3} \mathrm{CFU} / \mathrm{g}$ body weight for 21 days. Survival of mice infected with $1 \times 10^{2} \mathrm{CFU} / \mathrm{g}$ ( $n=6$ per group) or $1 \times 10^{3} \mathrm{CFU} / \mathrm{g}$ body weight ( $n=8$ per group) is shown as Kaplan-Meyer curve and curves were compared using the two-sided Log-rank (Mantel-Cox) test. $p$-values are shown in the graph. $\mathbf{b}$ Representative images of PAS stained histological cross sections of kidneys from moribund immunocompetent or immunosuppressed mice infected with $10^{4} \mathrm{CFU} / \mathrm{g}$ body weight of WT or eed1 $\Delta / \Delta$ mutant. Immunocompetent and immunosuppressed uninfected control mice were sacrificed $7 \mathrm{~d}$ after mock infection. Black arrows point towards purple stained C. albicans hyphae (WT) or yeast (eed1 $\Delta / \Delta$ mutant), white arrows towards immune cells infiltrating the renal tissue. Scale bar represents $20 \mu m$ and applies to all images. c Organ fungal burden of immunosuppressed mice infected with $1 \times 10^{2} \mathrm{CFU} / \mathrm{g}$ body weight $12 \mathrm{~h}$ and $18 \mathrm{~h}$ post infection and when moribund (mor). d Quantification of kidney injury by measuring and normalizing urinary KIM-1 to urinary creatinine level. c, d Two independent experiments, $n=6$, except for eed $1 \Delta / \Delta$ mutant $12 h, n=4$; controls, $n=4$. Data are shown as median with interquartile range and were compared using the two-sided Mann-Whitney test. $p$-values are shown in the graph. $\mathbf{d} p$-values above bars represent significant changes in comparison to the uninfected control. Source data are provided as a Source Data file.

hyphae-driven direct damage can be compensated by enhanced yeast cell growth. The exact molecular mechanisms by which absence of EED1 influences both morphogenesis and growth on alternative carbon sources remains unknown; however, it should be noted that retention of some level of virulence in the absence of hyphal elongation is not a unique feature of EED1 deficient strains. Homozygous deletion of UME6, resulting in a similar filamentation defect as observed for the eed $1 \Delta / \Delta$ mutant, leads to significantly attenuated virulence, but still causes lethal infections in mice ${ }^{70}$. Virulence of a $s f l 2 \Delta / \Delta$ mutant was comparable to the WT despite a filamentation defect ${ }^{71}$. In contrast to the eed $1 \Delta / \Delta$ mutant, systemic infection with the $s f 2 \Delta / \Delta$ mutant, however, did not result in increased fungal burden, and some filamentation occurs in the absence of SFL2 $2^{71,72}$. The role of SFL2 for interaction with immune cells has not been investigated so far, and it thus remains unclear if differences in immunopathology contribute to the virulence of the $s f 2 \Delta / \Delta$ mutant. Furthermore, a screen of a $C$. albicans deletion library identified mutants with defects in filamentation but with unaltered infectivity; ${ }^{73}$ a detailed analysis of these mutants might reveal additional strains for which virulence in murine systemic candidiasis models does not depend on filamentation.

Of note, significantly higher CFUs in kidneys were also observed for tet-NRG1- yeast on day 3 after systemic infection compared to both the parental strain (Supplementary Fig. 4d) and the same strain with doxycycline $(p=0.001)$, consistent with observations by Saville et al. ${ }^{14}$. However, the fungal burden of tetNRG1- yeast was approximately 1-log lower than for t-EED1+ yeast at this time point (mean $3.19 \times 10^{5} \pm 2.5 \times 10^{5}$ compared to $3.45 \times 10^{6} \pm 1.15 \times 10^{5}$ ), and declined over time (Supplementary Fig. 4d). This indicates that while increased proliferation in vivo might be a feature shared by different filament-deficient strains, it quantitatively differs; the lower fungal burden resulting from infection with tet-NRG1 yeast compared to t-EED1 yeast is likely one factor contributing to the difference in virulence between these two strains. In addition to metabolic fitness, resistance to host defense mechanisms determines the extent to which $C$. albicans can proliferate in vivo. While C. albicans locked in the yeast form by constitutive expression of NRG1 (tet-NRG1) were avirulent in immunocompetent mice in this and previous studies $^{14,74}$, the same strain was capable of inducing lethal infection in mice rendered leukopenic by combined treatment with cyclophosphamide and cortisone acetate ${ }^{75}$. In these mice, the yeast-locked strain reached a significantly higher fungal burden than the corresponding filamentous strain ${ }^{75}$, which was also higher than observed in immunocompetent animals in this study and by others ${ }^{14}$. Furthermore, in the same study the fungal load observed in mice with different types of immunosuppression and infected with the filamentous strain was comparable at the humane endpoint, even though this was reached at different time points after infection ${ }^{75}$. Similarly, MacCallum and Odds ${ }^{76}$ observed comparable kidney burden in mice at the humane endpoint even if animals were challenged with different infectious doses and survived for a different duration. Together, this suggests that a certain number of fungal cells can be tolerated within the kidney, and that this threshold is higher for yeast than for hyphae.

Comparison of tet-NRG1 and EED1-deficient strains furthermore indicates that, despite a shared morphology, different yeast strains display substantial differences in the ability to proliferate in vivo in the presence of functional innate immunity.

To our knowledge, this is the first study showing that increased metabolic fitness of $C$. albicans not only contributes to virulence in hematogenously disseminated candidiasis, but that enhanced proliferation of yeast cells can result in pathogenesis and mortality indistinguishable from infection with hyphae-forming WT and $\mathrm{t}-\mathrm{EED} 1-$ strains. Of note, the eed $1 \Delta / \Delta$ mutant caused $100 \%$ mortality in a systemic infection model in immunosuppressed mice, although delayed compared to the WT. In the absence of hypha-mediated damage and overt immunopathology, this indicates that rapid proliferation resulting in high organ fungal loads might be sufficient to drive pathogenesis. Previous studies have reported similar results: tet-NRG1 yeast, which are avirulent in immunocompetent mice (Supplementary Fig. $4^{14}$ ), can cause lethal infection in immunosuppressed mice ${ }^{75}$. Whether this was due to increased fungal burden was not determined. The relevance of fungal load for pathogenesis is furthermore supported by the fact that the course of disease and rate of mortality in mice with systemic candidiasis is highly dependent on the initial infection dose ${ }^{76,77}$. Furthermore, by adjusting the infectious dose of different strains Odds et al. achieved a comparable mean survival time of mice infected either with C. albicans SC5314 or an isolate (RV4688) that displayed less filamentation in the murine kidney. Interestingly, less filamentation of RV4688 also coincided with a higher fungal burden compared to SC5314 in this study ${ }^{77}$.

Considering that immunosuppression is a major risk factor for the development of candidemia ${ }^{78}$ the findings in this study might provide some explanation for the virulence of non-albicans Candida species, such as C. glabrata and C. auris, that do not form true hyphae $\mathrm{e}^{79,80}$. Interestingly, the yeast form is the virulent cell type in most pathogenic dimorphic fungi, such as Histoplasma spp. and Blastomyces spp., that grow as mycelia in the environment but switch to yeast upon entering the host ${ }^{81}$. While the pathogenicity factors and pathogenesis mechanisms employed by these yeast cells differ significantly from $C$. albicans yeast, this underscores the general concept that yeast cells are not per se less virulent than hyphae. 


\section{Methods}

C. albicans strains, strain construction and growth conditions. The t-EED1 strain was generated in the THE $1^{82}$ background. Therefore, the URA3-tetracyclineregulable (TR) promoter region was amplified from p99CAU1 ${ }^{82}$ using primers Eed1-TET-F and Eed1-TET-R (Supplementary Table 1). Fragments were used to replace the endogenous promotor of one allele of EED1. The second allele of EED1 was deleted using the SAT1 flipping method ${ }^{83}$ with plasmids already containing the EED1-flanking regions used to generate the homozygous eed $1 \Delta / \Delta$ deletion mutant M1315 ${ }^{7}$. Transformants were selected on YPD with $200 \mathrm{mg} / \mathrm{ml}$ nourseothricin ${ }^{83}$ and were verified by PCR and Southern Blot analysis.

The C. albicans clinical isolate SC5314 ${ }^{84}$, the isogenic eed $1 \Delta / \Delta$ mutant $^{7}$, t-EED1 and the respective parental strain THE1-CIp10 ${ }^{18}$ were maintained as glycerol stocks and grown on YPD ( $1 \%$ yeast extract, $2 \%$ peptone, $2 \%$ glucose) agar plates. Single colonies were inoculated into liquid YPD and grown overnight at $30^{\circ} \mathrm{C}$ with horizontal shaking at $180 \mathrm{rpm}$. When needed, C. albicans cells were grown to exponential phase by diluting liquid cultures to an optical density at $600 \mathrm{~nm}$ $\left(\mathrm{OD}_{600}\right)$ of 0.2 , followed by incubation at $30^{\circ} \mathrm{C}$ and $180 \mathrm{rpm}$ for $3-4 \mathrm{~h}$. Cultures were washed twice with phosphate buffered saline (PBS) prior to experiments.

For infection experiments, fresh C. albicans colonies were inoculated into liquid YPD and grown to late exponential phase $(14-16 \mathrm{~h})$ at $30^{\circ} \mathrm{C}$ with horizontal shaking at $180 \mathrm{rpm}$. Doxycycline hyclate $(50 \mu \mathrm{g} / \mathrm{ml}$; Sigma Aldrich) was added to tEED1 cultures to prevent hypha formation. Cells were washed twice with sterile PBS and resuspended in Dulbecco's Phosphate Buffered Saline (DPBS, Gibco), counted using a hemocytometer and adjusted to the desired concentrations in DPBS. Infectious doses were confirmed by serial dilutions and plating on YPD agar plates.

Morphology of tetracycline-regulable strains in vitro. To investigate fungal morphology of the tet-regulable t-EED1 strain in vitro, THE1-CIp10 and t-EED1 were streaked on YPD plates in the absence or presence of $50 \mu \mathrm{g} / \mathrm{ml}$ doxycycline. Plates were incubated under non-hypha-inducing conditions at $25^{\circ} \mathrm{C}$ for 2 days before pictures were taken from single colonies with an inverse microscope (Axio Vert.A1; Zeiss). To test for morphology under hypha-inducing conditions, $5 \times 10^{4}$ cells of the strains were seeded in RPMI1640 in the absence or presence of $50 \mu \mathrm{g} / \mathrm{ml}$ doxycycline per well in 12 -well plates and incubated at $37^{\circ} \mathrm{C}$ and $5 \% \mathrm{CO}_{2}$. Pictures were taken after various time points by inverse microscopy.

Growth curves. To evaluate growth in the presence of different carbon sources SC5314 and the eed $1 \Delta / \Delta$ mutant were diluted to $\mathrm{OD}_{600}$ of 0.1 in YPD medium with 2 or $0.1 \%$ glucose or in SD minimal medium $(0.67 \%$ yeast nitrogen base; BD Biosciences) in the presence of $2 \%$ glucose, $0.1 \%$ glucose, $2 \% \mathrm{~N}$-acetyl-glucosamine (GlcNAc; Sigma-Aldrich), 2\% sodium-DL-lactate (Sigma Aldrich), 2\% potassium acetate (Merck), $2 \%$ citric acid monohydrate (Roth) or $2 \%$ casamino acids (BD Biosciences). For testing of proteolytic activity, C. albicans strains were grown in SD medium overnight, washed twice with $\mathrm{PBS}$ and $\mathrm{OD}_{600}$ was set to 0.1 in YCBBSA (1.17\% Yeast Carbon Base (BD Biosciences), 1\% glucose, 0.5\% BSA (Serva)), $\mathrm{pH}$ 4.0. For growth in kidney homogenates, kidneys of uninfected mice were removed aseptically, homogenized and diluted to $25 \mathrm{mg} / \mathrm{ml}$ in DPBS and filtered through $70 \mu \mathrm{m}$ and $40 \mu \mathrm{m}$ cell strainers before filter sterilization. Growth was recorded by measuring $\mathrm{OD}_{600}$ in a microplate reader at $37^{\circ} \mathrm{C}$. Measurements were performed in $30 \mathrm{~min}$ intervals over a course of $60 \mathrm{~h}$. Blank values were subtracted from all measurements.

Sample preparation for RNA isolation, RNA sequencing and analysis of data. For RNAseq, overnight cultures of $C$. albicans WT SC5314 and eed1 $\Delta / \Delta$ mutant were grown in SD with $2 \%$ glucose at $30^{\circ} \mathrm{C}$ and $180 \mathrm{rpm}$ (Supplementary Fig. 13a). To synchronize cultures cells were inoculated at an $\mathrm{OD}_{600}$ of 0.1 in SD with $2 \%$ glucose and grown at $30^{\circ} \mathrm{C}$ and horizontal shaking at $180 \mathrm{rpm}$. After $10 \mathrm{~h}$ samples for the $0 \mathrm{~h}$ time point were taken and cells were transferred to SD medium containing $2 \%$ of citrate (Roth) or $2 \%$ of casamino acids (CAA; BD Bacto) as sole carbon source at an $\mathrm{OD}_{600}$ of 0.2 in individual flasks for each time point. Cells were grown at $37^{\circ} \mathrm{C}$ and $180 \mathrm{rpm}$. After $2 \mathrm{~h}, 6 \mathrm{~h}$ and $12 \mathrm{~h}$ samples were removed from the cultures and cell pellets for RNA isolation were obtained by centrifugation at $20,000 \times g$ for $3 \mathrm{~min}$ and were immediately frozen in liquid nitrogen. Additional samples were taken at these and intermediate time points to determine the optical density at $600 \mathrm{~nm}$, dry mass and morphology of fungal cells. For the determination of dry mass, nylon Whatman ${ }^{\circledR}$ membrane filters with a pore size of $0.2 \mu \mathrm{m}$ were dried at $55^{\circ} \mathrm{C}$ for $24 \mathrm{~h}$ in a hybridization oven, weight and placed on a bottle top vacuum filter. Cells were loaded on the membrane by filtration and washed with $\mathrm{ddH}_{2} \mathrm{O}$. After drying for additional $24 \mathrm{~h}$, membranes were weighed again and dry mass was calculated. Experiments were conducted in triplicates and RNA isolation was performed as previously described ${ }^{7}$. In brief, pellets were resuspended in $400 \mu \mathrm{l}$ AE-buffer ( $50 \mathrm{mM}$ sodium acetate, $10 \mathrm{mM}$ EDTA) and $40 \mu \mathrm{l} 10 \% \mathrm{SDS}$. An equal volume of phenol/chloroforme/isoamylalcohol was added followed by incubation at $65^{\circ} \mathrm{C}$ for $5 \mathrm{~min}$. Homogenous solutions were frozen at $-80^{\circ} \mathrm{C}$ for $10 \mathrm{~min}$, transferred to $65^{\circ} \mathrm{C}$ for $5 \mathrm{~min}$. Freezing and thawing was repeated once. Solutions were centrifuged for $10 \mathrm{~min}$ at $20,800 \times g$ and the upper phase was transferred into a new reaction tube. $10 \%$ volume $3 \mathrm{M}$ sodium acetate ( $\mathrm{pH} 5.3$ ) and 1 volume 2propanol were added. Precipitation of RNA was carried out for $30 \mathrm{~min}$ at $-20^{\circ} \mathrm{C}$.
After centrifugation for $10 \mathrm{~min}$ at $12,000 \mathrm{~g}$ the supernatant was discarded and RNA pellets were washed twice with $70 \%$ ethanol. RNA was solved in RNase free water RNA quantity was determined with a Nanodrop ND1000 (Peqlab) and quality was assessed using an Agilent 2100 Bioanalyzer (Agilent Technologies). Library preparation and RNA sequencing was carried out at Novogene (UK) Company Limited. Sequencing was performed using an Illumina NovaSeq 6000 system to obtain $150 \mathrm{bp}$ paired-end reads.

Mapping of the fastq files delivered by the company (raw data are accessible at NCBI under BioProject accession number PRJNA714826, https://www.ncbi.nlm. nih.gov/bioproject/PRJNA714826) and counting of the gene transcription reads was performed using the European Galaxy server ${ }^{85}$ that is providing an environment and sets of tools for the following analysis steps: First, FastQC was used to assess the quality of the sequences and Cutadapt was applied. Sequences were mapped to the genome of C. albicans WT (SC5314) using the RNA-Star tool, the "length of the genomic sequence around annotated junctions" parameter was set to 149 . From that analysis, bam files were constructed that were used to quantify gene counts with the FeatureCount function. The reverse stranded bam files were processed allowing for fragment counts but not multimapping. The minimum mapping quality per read was set to 10 . Final count files were analyzed in $\mathrm{R}$, using the Deseq 2 package ${ }^{86}$ that allows searching for differentially expressed genes (DEGs) by comparing the count tables of different conditions. For this purpose, transcription profiles of the mutant were compared to the WT at the $0 \mathrm{~h}$ time point, as well as for each time point in medium containing citrate or casamino acids. The principal component analysis was done using the PCA function from the Deseq2 package in R. All genes were used for the calculation. Gene Ontology (GO) term enrichment analysis was performed from significantly up- or downregulated genes $\left(+\right.$ or $-\log _{2} 2$ and adjusted $p$-value $\left.<0.05\right)$ in eed $1 \Delta / \Delta$ mutant compared to WT using the CGD GO Term Finder ${ }^{87}$. Based on the analysis of GO terms with REVIGO ${ }^{88}$ graphs were created using cytoscape ${ }^{89}$. Venn diagrams were created using Venny2.1 (https://bioinfogp.cnb.csic.es/tools/venny/).

Mice. All animal experiments were performed in accordance with European and German regulations. Protocols were approved by the Thuringian authority and ethics committee (Thüringer Landesamt für Verbraucherschutz, permit numbers: HKI-19-003, 03-007/13, 03-002/11, 03-004/15, 03-008/13). Eight- to ten-week-old female specific-pathogen-free BALB/c mice (16 to $18 \mathrm{~g}$ ), purchased from Charles River (Germany), were housed in groups of five in individually ventilated cages at $22 \pm 1{ }^{\circ} \mathrm{C}, 55 \pm 10 \%$ relative humidity, $12 \mathrm{~h} / 12 \mathrm{~h}$ dark/light cycle, with free access to food and water and autoclavable mouse houses as environmental enrichment.

Intraperitoneal and systemic infection model. For intraperitoneal infection and survival analyses after intravenous infection with THE1-CIp10, t-EED1 and tetNRG1, mice received drinking water containing $5 \%$ sucrose without $(-)$ or with (+) $2 \mathrm{mg} / \mathrm{ml}$ doxycycline starting 3 days prior to infection. Water was replaced every two days. The low acceptance of doxycycline containing water resulted in a loss of body weight in the doxycycline group only, indicating possible dehydration. This could have aggravated the consequences of impaired renal function caused by systemic infection and likely explains while mice infected with THE1-CIp10 reached the humane endpoints earlier if they received doxycycline (Fig. 2c). Therefore, in further experiments mice received a diet containing $625 \mathrm{mg} / \mathrm{kg}$ doxycycline (Envigo Teklad, catalog no. TD.120769). Food was replaced every 5 days; acceptance was high, resulting in body weights comparable to the nondoxycycline groups. For the intraperitoneal infection model, mice were infected intraperitoneally with $1 \times 10^{8} \mathrm{CFU}$ in $500 \mu \mathrm{l}$ DPBS and mice were humanely sacrificed $24 \mathrm{~h}$ post infection. For hematogenously disseminated candidiasis mice were infected with $1 \times 10^{2}$ to $1.25 \times 10^{5} \mathrm{CFU} / \mathrm{g}$ body weight in $100 \mu \mathrm{LPBS}$ via the lateral tail vein at day 0 . For survival experiments, mice were euthanized when showing signs of severe illness (details described below), and these animals are referred to as "moribund". Groups of mice $(n=5)$ were sacrificed 6, 24, 48 and $72 \mathrm{~h}$ post infection with $2.5 \times 10^{4} \mathrm{CFU} / \mathrm{g}$ body weight for analysis of fungal burden, immune cell infiltration, renal cytokines, serum and urinary marker protein progression during the acute phase of infection. Uninfected control mice received (ctr + ) or did not receive doxycycline (ctr-) containing food. Time point experiments were repeated two to three times.

Induction of neutro- and monocytopenia. To deplete neutrophils and monocytes $100 \mu \mathrm{g}$ of the InVivo Plus anti-mouse Ly6G/Ly6C (Gr-1) monoclonal antibody (clone RB6-8C5; BioXcell) in $100 \mu$ DPBS were administered intraperitoneally $24 \mathrm{~h}$ prior to infection and every $48 \mathrm{~h}$ thereafter. Mice were systemically infected with $C$ albicans WT (SC5314) and the eed $1 \Delta / \Delta$ mutant using $1 \times 10^{2}, 1 \times 10^{3}$ or $1 \times 10^{4}$ $\mathrm{CFU} / \mathrm{g}$ body weight. Successful depletion of peripheral neutrophils (neutropenia defined as less than $200 \mathrm{PMNs} / \mu$ blood $^{90}$ ) and monocytes was confirmed when animals reached humane endpoints by white blood cell differential count using the hematology analyzer BC-5300Vet (Mindray; Supplementary Fig. 11). Uninfected control groups $(n=2)$ did or did not receive RB6-8C5 and were sacrificed 7 days after they were mock-infected with $100 \mu \mathrm{l}$ DPBS into the lateral tail vein.

Murine model of gastrointestinal colonization and dissemination. To avoid environmental contamination, cages, bedding, bottles and drinking water were 
sterilized prior to use and mice were handled exclusively in laminar flow hoods. Mice received sucrose-containing drinking water and sucrose concentration was increased from $2.5 \%$ starting $7 \mathrm{~d}$ prior to infection for $2 \mathrm{~d}$ to $5 \%$ for $1 \mathrm{~d}$. From day -4 until the end of the experiment mice received antibiotics to reduce the intestinal bacterial flora: $1500 \mathrm{U} / \mathrm{ml}$ penicillin and $2 \mathrm{mg} / \mathrm{ml}$ streptomycin were added to $7.5 \%$ sucrose-containing drinking water that was replaced daily; Mice were fed with chow containing $625 \mathrm{mg} / \mathrm{kg}$ doxycycline sterilized by irradiation. On day 0 , mice were inoculated by gavage with $100 \mu$ DPBS containing $5 \times 10^{7}$ C. albicans WT (SC5314) or eed1 $\Delta / \Delta$. Mice were divided in two groups: one group was only colonized whereas in the other group dissemination was induced by injecting 200 $\mathrm{mg} / \mathrm{kg}$ body weight cyclophosphamide (Endoxan, Baxter) intraperitoneally on day 7 and 10 post infection. Successful depletion of immune cells was confirmed by white blood cell differential count using the hematology analyzer. Feces were collected from individual mice on day 2, 4, 7 and 14, weighed and plated on YPD agar with or without $80 \mu \mathrm{g} / \mathrm{ml}$ chloramphenicol for determination of fungal and bacterial CFUs, respectively. On the end of the experiment (14 days p.i.) mice were humanely sacrificed and fungal burden were determined in liver and kidney.

Clinical monitoring and scoring. Body weight and body surface temperature were recorded daily. After infection the health status of the mice was checked at least twice a day. For RB6-8C5 treated immunosuppressed mice, health status was recorded every $3 \mathrm{~h}$ for $39 \mathrm{~h}$ and every $6 \mathrm{~h}$ thereafter. An additive clinical score was determined to evaluate disease severity. For intraperitoneal infection the following parameters were included: fur, coat and posture (normal, 0 ; fur mildly ruffled, 1 ; fur strongly ruffled, 2; fur strongly ruffled and hunched posture, 3), lethargy (absent, 0 ; mild, 1; moderate, 2; severe, 3), intraabdominal fibrin exudation (none, 0 ; single, small flocks, 1 ; multiple adhering flocks, removable, 2; multiple adhering flocks, removing causes damage to organ, 3), presence of other symptoms like ocular discharge, diarrhea (absent, 0; present, 1). The maximum possible score was 10. For systemic infections and the colonization and dissemination model the following parameters were included: fur (normal, 0 ; slightly ruffled, 1 ; ruffled, 2), lethargy (absent, 0 ; mild, 1; moderate, 2; severe, 3), body temperature (normal, 0; moderately increased, 1; increased, 2 ; hypothermia, 3). The maximum possible score was 8 . Mice were humanely sacrificed when they reached the humane endpoints defined as (i) severe lethargy, (ii) hypothermia, or (iii) a cumulative clinical score of $\geq 5$. Mice were euthanized with an overdose of ketamine (100 $\mu \mathrm{l} \mathrm{of} 100 \mathrm{mg} /$ $\mathrm{ml})$ and xylazine $(25 \mu \mathrm{l}$ of $20 \mathrm{mg} / \mathrm{ml})$ applied intraperitoneally followed by blood withdrawal.

Determination of serum and urinary biomarkers. Blood was collected by cardiac puncture (intraperitoneal infection and survival experiment) or via the vena cava inferior from mice euthanized at defined time points. Serum enzyme levels of pancreatic amylase and alanine aminotransaminase (ALT) were measured using the EuroLyser CCA 180 Vet system (QinLAB Diagnostik) according to standard methods recommended by the International Federation of Clinical Chemistry. The Mouse TREM-1 ELISA Kit (RayBiotech), DetectX ${ }^{\circledR}$ Urea Nitrogen (BUN) Detection Kit (Arbor Assays), Mouse Lipocalin-2 (NGAL) ELISA Kit (RayBiotech) and Detect $\mathrm{X}^{\circledast}$ Serum Creatinine Kit (Arbor Assays) were used to measure the respective parameters in serum of mice. Urine of mice was collected from mice euthanized 24, 48 and $72 \mathrm{~h}$ p.i. from moribund and uninfected mice. Either spontaneous urine was collected or gentle trans-abdominal pressure was applied onto the bladder and urine was collected using untreated glass capillary tubes. Urinary KIM-1 and creatinine levels were measured using the Mouse TIM-1 ELISA Kit (RayBiotech) and the Creatinine Parameter Assay Kit (R\&D Systems), respectively. KIM-1 levels were normalized to urinary creatinine to account for differences in urinary concentration.

Quantification of immune cells by flow cytometry. To evaluate immune cell infiltration during the course of infection, organs were perfused with normal saline after withdrawal of blood. Organs were removed and weighed. One half of each kidney was cut into small pieces and digested in the presence of collagenase D $(30 \mu \mathrm{g} / \mathrm{ml}$; Sigma Aldrich) and DNase I $(0.7 \mathrm{mg} / \mathrm{ml}$; Sigma Aldrich) in RPMI (RPMI 1640; Gibco) supplemented with 10\% fetal bovine serum (FBS; Bio\&SELL), Pen Strep (100 U/ml Penicillin and $100 \mu \mathrm{g} / \mathrm{ml}$ Streptomycin; Life Technologies), and $1 \mathrm{mM}$ sodium pyruvate (Gibco) for $30 \mathrm{~min}$ at $37^{\circ} \mathrm{C}$ with moderate horizontal shaking $(70 \mathrm{rpm})$. Single cells were obtained by passing the digested tissue through a $70 \mu \mathrm{m}$ cell strainer. Cells were washed and erythrocytes were lysed by addition of red blood cell lysis buffer $\left(0.15 \mathrm{mM} \mathrm{NH}_{4} \mathrm{Cl}, 10 \mathrm{mM} \mathrm{KHCO} 3,1 \mathrm{mM} \mathrm{Na}_{2} \mathrm{EDTA}\right.$, pH 7.2). Remaining cells were washed, resuspended in 70\% Percoll (GE Healthcare) and layered under $30 \%$ Percoll. Leukocytes were enriched by density gradient centrifugation $(400 \mathrm{~g}, 20 \mathrm{~min}$, room temperature (RT), acceleration 1, deceleration 0 ). Leukocytes were collected from the interphase, washed with PBS and volumes were determined. Cells were transferred in a 96-well plate. Leukocytes were stained for flow cytometric analysis and acquired on a FACSVerse (BD Biosciences). The following antibodies were used: PerCP anti-CD45 (30-F11, BD Biosciences), APC anti-CD11b (M1/70, eBioscience), eFluor anti-CD335 (29A1.4, eBioscience), FITC anti-F4/80 (BM8, eBioscience), PE anti-CD11c (N418, eBioscience), PE-Cy7 antiMHCII (M5/114.15.2 eBioscience), eFluor anti-Ly-6C (HK1.4, eBioscience) FITC anti-CD19 (1D3, BD Biosciences), PE-Cy7 anti-CD3e (145-2C11, eBioscience). Fc receptors were blocked by addition of anti-mouse CD16/32 (93; BioLegend) 1:50 to the staining mixture. Dead cells were excluded from analysis using the Fixable Viability Dye eFluor ${ }^{\circledast} 506$ (eBioscience) prior to specific antibody staining. A detailed description of the gating strategy is provided in Supplementary Fig. 19. Data were analyzed using FlowJo V.10.0.8 software.

Histopathology and immunohistochemistry. For histology, longitudinal sections of kidneys were fixed with buffered formalin and embedded in paraffin, cut into $3-4 \mu \mathrm{m}$ slices, and stained with periodic acid-Schiff (PAS) staining according to standard protocols. Apoptotic cells in the kidney were detected by immunohistochemistry using the ApopTag in situ apoptosis detection kit (EMD Millipore) following the manufacturer's directions. Briefly, paraffin-embedded sections were rehydrated in Histo-Clear II (National Diagnostics) and alcohols followed by washing with phosphate-buffered saline (PBS). The sections were pre-treated with $20 \mu \mathrm{g} / \mathrm{ml}$ Proteinase K (Ambion) in PBS for $15 \mathrm{~min}$ at RT. Endogenous peroxidases were blocked by incubating slides for $15 \mathrm{~min}$ in $3 \%$ hydrogen peroxide. Sections were incubated with equilibration buffer (EMD Millipore) for $30 \mathrm{~s}$ at RT, followed by terminal deoxynucleotidyl transferase (TdT; EMD Millipore) incubation at $37^{\circ}$ $\mathrm{C}$ for $1 \mathrm{~h}$. Sections were further exposed to anti-Digoxigenin (EMD Millipore, Cat Number S7100) for $30 \mathrm{~min}$ at RT, and the positive reaction was visualized with DAB 3, 3-diaminobenzidine (DAB) substrate (Thermo Scientific). After counterstaining the specimens with $0.5 \%$ methyl green (Sigma), they were imaged by bright field microscopy. For quantification, apoptotic areas were quantified using PROGRES GRYPHAX ${ }^{\oplus}$ software (Jenoptik).

\section{Determination of organ fungal burden and in vivo cytokine production} Weighed organs were homogenized in MPO buffer $(200 \mathrm{mM} \mathrm{NaCl}, 5 \mathrm{mM}$ EDTA, $10 \mathrm{mM}$ TRIS pH 8, 10\% glycerol, $1 \mathrm{mM}$ PMSF, $28 \mu \mathrm{g} / \mathrm{mL}$ Aprotinin, $1 \mu \mathrm{g} / \mathrm{ml}$ Leupeptin) using an UltraTurrax (Ika). Homogenates were serially diluted and plated onto YPD plates containing $80 \mu \mathrm{g} / \mathrm{ml}$ chloramphenicol (Roth) for enumeration of CFU. Supernatants were generated by centrifugation $\left(1500 \mathrm{~g}, 4^{\circ} \mathrm{C}\right.$, $15 \mathrm{~min}$ ) and frozen at $-80^{\circ} \mathrm{C}$ until determination of cytokine concentrations. Cytokines were quantified using a customized ProcartaPlex ${ }^{\text {Tx }}$ Mix\&Match Mouse 12-plex (eBioscience; cytokines that were included: GRO-alpha (KC), IFN- $\gamma$, IL-1 $\beta$, IL-10, IL-12p40, IL-18, IL-6, IP-10, MCP-1, MIP-1a, RANTES, TNF- $\alpha$.) The plex was performed according to manufacturer's instructions using a Luminex Magpix system (Luminex Corporation).

\section{Neutrophil isolation from bone marrow and differentiation of bone marrow-} derived macrophages. Bone marrow was obtained from 8-20 week old female $\mathrm{BALB} / \mathrm{c}$ mice as described previously ${ }^{91}$. Briefly, mice were euthanized by cervical dislocation and femora, tibiae and humeri were removed and placed in RPMI supplemented with Pen Strep. Bone marrow was flushed with supplemented RPMI and single cell suspensions were obtained by continuous pipetting. Bone residues were removed by filtration through a $40 \mu \mathrm{m}$ pore-size filter. Cells were pelleted and erythrocytes were lysed by addition of RBC lysis buffer. Cells were resuspended in Hanks' balanced saline solution without $\mathrm{Ca}$ and $\mathrm{Mg}$ (HBSS; Lonza). Mature neutrophils were purified using a discontinuous Percoll gradient consisting of 52\%, $69 \%$, and $78 \%$ Percoll in HBSS-. Mature neutrophils were recovered from the $69 \% /$ $78 \%$ interphase after centrifugation $\left(1500 \mathrm{~g}, 4^{\circ} \mathrm{C}, 30 \mathrm{~min}\right.$, acceleration 2, deceleration 2), washed and resuspended in HBSS ${ }^{-}$. Neutrophils were counted using the hematology analyzer. Purity of neutrophils was confirmed by flow cytometry to be between $89-95 \%$. For differentiation into macrophages, bone marrow cells were seeded at a density of $5 \times 10^{6}$ cells in $175 \mathrm{~cm}^{2}$ cell culture flasks in RPMI containing $10 \%$ heat-inactivated (h.i.; $30 \mathrm{~min}$ at $56^{\circ} \mathrm{C}$ ) FBS, Pen Strep and $40 \mathrm{ng} / \mathrm{ml}$ recombinant murine M-CSF (ImmunoTools). Cells were incubated in a humidified incubator at $37^{\circ} \mathrm{C}$ with $5 \% \mathrm{CO}_{2}$ and medium was exchanged every 2-3 days. After 7 days, adherent cells were detached in RPMI + FBS by scrapping. Viable cells were counted using trypan blue exclusion and diluted to desired concentrations. For phagocytosis assays $5 \times 10^{5}$ neutrophils or macrophages were allowed to adhere to sterile coverslips in a 24 -well plate for $1-2 \mathrm{~h}$ at $37^{\circ} \mathrm{C}, 5 \% \mathrm{CO}_{2}$ in a humidified incubator. To increase the adherence of neutrophils, coverslips were pre-treated with $0.1 \%$ gelatin and incubated at $4{ }^{\circ} \mathrm{C}$ overnight. Wells were washed twice with PBS before seeding. For cytokine measurement, survival and damage assays $8 \times 10^{4}$ neutrophils or macrophages were seeded in 96-well plates in RPMI supplemented with $1 \%$ mouse serum. Cells were allowed to adhere to the substrate by culturing them for $1-2 \mathrm{~h}$ at $37^{\circ} \mathrm{C}, 5 \% \mathrm{CO}_{2}$ in a humidified incubator prior to infection.

Phagocytosis, survival and damage assays. To quantify phagocytosis, cells were infected with C. albicans at a multiplicity of infection (MOI) of 1 in the presence of $1 \%$ murine serum in a total volume of $500 \mu \mathrm{l}$. After $1 \mathrm{~h}$ of co-incubation at $37^{\circ} \mathrm{C}$ with $5 \% \mathrm{CO}_{2}$, cells were fixed with $2 \%$ paraformaldehyde. Extracellular C. albicans cells were stained with Alexa Fluor 647-conjugated Concanavalin A (Thermo Fisher Scientific) for $30 \mathrm{~min}$, intra- and extracellular fungal cells were stained with Calcofluor White (Sigma-Aldrich) after permeabilization of immune cells with $0.5 \%$ Triton X-100. Coverslips were mounted with ProLong Gold antifade reagent (Thermo Fisher Scientific) and fluorescence images were recorded using the Axio Observer.Z1 (Carl Zeiss Microscopy). The phagocytic index was determined by counting the numbers of $C$. albicans cells phagocytosed by 100 immune cells. 
Fungal survival in the presence of immune cells was determined by infecting macrophages or neutrophils with C. albicans (MOI1) in the presence of $1 \%$ murine serum in a total volume of $150 \mu \mathrm{l}$. After 2 or $6 \mathrm{~h}$, immune cells were lysed by addition of $50 \mu \mathrm{l} 5 \%$ Triton X-100. Fungal cells were resuspended by rigorously pipetting and lysates were diluted and plated onto YPD plates and incubated for $48 \mathrm{~h}$ at $37^{\circ} \mathrm{C}$. Survival rates were calculated by normalization from control wells containing no immune cells and the increase in fungal CFU was calculated by normalization to the starting inoculum for cells in the presence or absence of BMDMs. Fungal morphology was recorded by inverse microscopy using an Axio Vert.A1 microscope (Zeiss) after various time points. To quantify damage and TNF- $\alpha$, BMDMs were co-incubated with C. albicans (MOI1) for $24 \mathrm{~h}$. For total LDH release (high control), BMDMs were lysed by addition of $20 \mu \mathrm{l} 5 \%$ Triton X100 , incubated for $10 \mathrm{~min}$ at $37^{\circ} \mathrm{C}$. Supernatants were obtained by centrifugation at $300 \mathrm{x}$ g for $10 \mathrm{~min}$. LDH was quantified using the Cytotoxicity Detection Kit (Roche) and TNF- $\alpha$ was quantified by ELISA (Ready-SET-Go, eBioscience) according to manufacturer's instructions.

Cytokine and ROS production. Macrophages and neutrophils were infected with living or heat-killed (HK; $70^{\circ} \mathrm{C}, 10 \mathrm{~min}$ ) C. albicans WT cells (MOI1) in a total volume of $200 \mu$ l. Unstimulated immune cells and cells treated with $100 \mathrm{nM}$ phorbol 12-myristate 13-acetate (PMA; Sigma Aldrich) or $100 \mathrm{ng} / \mathrm{ml}$ lipopolysaccharide (LPS; Sigma Aldrich) served as negative and positive controls, respectively. After co-incubation for $24 \mathrm{~h}$ at $37^{\circ} \mathrm{C}$ with $5 \% \mathrm{CO}_{2}$ supernatants were recovered after centrifugation $\left(1500 \times g, 4^{\circ} \mathrm{C}, 15 \mathrm{~min}\right)$ and TNF- $\alpha$, IL- 6 and IL-10 were determined by commercially available ELISA kits (Invitrogen) according to manufacturer's instructions.

Total ROS accumulation by neutrophils was quantified by luminol-enhanced chemiluminescence. Therefore, $5 \times 10^{4}$ freshly isolated neutrophils were seeded into white clear-bottom 96-well plates (Corning) in RPMI without phenol red (Gibco). Cells were allowed to attach for $30 \mathrm{~min}$ at $37^{\circ} \mathrm{C}$ and $5 \% \mathrm{CO}_{2}$ prior to infection. Neutrophils were infected with C. albicans (MOI1) left untreated or were stimulated with PMA as positive control. Immediately after stimulation, $50 \mu \mathrm{l}$ of RPMI without phenol red containing $200 \mathrm{mM}$ luminol (Fluka) and $16 \mathrm{U}$ horseradish peroxidase (Sigma Aldrich) were added. Luminescence was recorded every $2.5 \mathrm{~min}$ for $190 \mathrm{~min}$ at $37^{\circ} \mathrm{C}$ in a Tecan Infinite microplate reader. The area under the curve was calculated with GraphPad Prism 7.

Epithelial cell infection. The following human epithelial cell lines were used in this study: Hepatic epithelial cells (HepaRG; Gibco) were maintained in William's Medium E with GlutaMAX and HepaRG Thaw, Plate \& General Purpose Medium Supplement; renal epithelial cells (A498; DSMZ) were cultivated in Minimum Essential Medium with L-glutamine supplemented with $10 \%$ h.i. FBS; oral epithelial cells (TR146; Episkin) were cultivated in Dulbecco's Modified Eagle Medium (DMEM) with high glucose supplemented with $10 \%$ h.i. FBS; intestinal epithelial cells (Caco-2 clone type C2BBe1; ATCC ${ }^{\oplus} \mathrm{CRL}-2102^{\mathrm{TM}}$ ) were maintained in DMEM supplemented with $10 \%$ h.i. FBS and $10 \mu \mathrm{g} / \mathrm{ml}$ human holotransferrin (Merck Millipore). Cells were cultured in a humidified incubator at $37^{\circ} \mathrm{C}$ with $5 \%$ $\mathrm{CO}_{2}$ under normoxic conditions $\left(21 \% \mathrm{O}_{2}\right)$ if not stated otherwise. In addition, $\mathrm{C} 2 \mathrm{BBe} 1$ cells were cultivated under hypoxic conditions $\left(1 \% \mathrm{O}_{2}\right)$ in a temperature controlled Hypoxystation (H35, Don Whitley Scientific) to mimic physiological intestinal $\mathrm{O}_{2}$ concentrations. For damage assays and the quantification of cytokines, cells were detached and $2 \times 10^{4}$ cells (TR146, A498) or $4 \times 10^{4}$ cells (HepaRG) were seeded in 96-well plates $2 \mathrm{~d}$ prior to infection. Cells were washed and infected with exponentially grown C. albicans strains at a MOI of 1 in a volume of $200 \mu \mathrm{l}$. Medium without fungal cells served as mock control. After $24 \mathrm{~h}$ of coincubation, supernatants were recovered after centrifugation $(200 \times g, 5 \mathrm{~min})$. To measure epithelial integrity and translocation, Corning ${ }^{\circledR}$ Transwell ${ }^{\circledR}$ polycarbonate membrane inserts with $5 \mu \mathrm{m}$ pore size and $6.5 \mathrm{~mm}$ in diameter were coated with $100 \mu \mathrm{l}$ of $10 \mu \mathrm{g} / \mathrm{ml}$ collagen I for $2 \mathrm{~h}$ at RT before they were washed twice and placed in a 24 -well plate filled with $600 \mu \mathrm{l}$ supplemented DMEM. $2 \times 10^{4}$ C2BBel cells were seeded in $200 \mu \mathrm{l}$ supplemented DMEM in inserts and cultivated for $14 \mathrm{~d}$ at $37^{\circ} \mathrm{C}, 5 \% \mathrm{CO}_{2}$ with $21 \% \mathrm{O}_{2}$ or $1 \% \mathrm{O}_{2}$. Medium was replaced on day 5 and every second day thereafter. Epithelial cells were infected by adding $1 \times 10^{5} \mathrm{C}$. albicans cells to the upper compartment and incubated for $24 \mathrm{~h}$ at the conditions mentioned above. To measure epithelial integrity, the trans-epithelial electrical resistance (TEER) was quantified using a chopstick electrode connected to the Epithelial Voltohmmeter EVOM2 (WPI) before and $24 \mathrm{~h}$ post infection. TEER measurements from inserts containing medium only served as blank values and were subtracted from all measurements. Supernatants of the upper compartment were kept for measurement of lactate dehydrogenase (LDH). To quantify the potential of the different $C$. albicans strains to translocate through the $\mathrm{C} 2 \mathrm{BBe} 1$ cell layer, $24 \mathrm{~h}$ after infection the lower compartment was treated with $20 \mathrm{U} / \mathrm{l}$ zymolyase (Amsbio) for $2 \mathrm{~h}$ at $37^{\circ} \mathrm{C}$ and $5 \% \mathrm{CO}_{2}^{22}$. Detached fungal cells were plated on YPD agar and CFUs were counted. Epithelial cell damage was quantified by measurement of LDH in supernatants using the Cytotoxicity Detection Kit (Roche). Uninfected cells served as negative control. For total cells lysis (high control) $10 \mu \mathrm{l}$ of 5\% Triton X-100 were added. Human IL-6 and IL-8 were quantified by ELISA (Invitrogen) according to the manufacturer's instructions.
Quantitative PCR. DNA was isolated from kidneys infected with either the WT (THE1-CIp10) or t-EED1 in the presence of doxycycline. Kidneys were homogenized and centrifuged for $15 \mathrm{~min}$ at $1500 \times \mathrm{g}$. DNA was extracted from pellets using the Yeast DNA Extraction Kit (Thermo Scientific) following manufacturer's instructions. For amplification of the C. albicans $18 \mathrm{~S}$ rRNA gene $R D N 18$ the following primers were used: sense amplification primer, 5'-GGACCCAGCCGAGCCTT-3' and antisense amplification primer, 5'-AAGTAAAAGTCCTGGTTCGCCA-3'30. Quantitative PCR was conducted using $1 \mu \mathrm{l}$ of template DNA and the QPCR Mix EvaGreen (Bio\&SELL) on a CFX 96 Real time System (BioRad). The following condition were used for product amplification: $95^{\circ} \mathrm{C}$ for $15 \mathrm{~min}, 40$ cycles of each $95^{\circ} \mathrm{C}$ for $15 \mathrm{~s}, 59^{\circ} \mathrm{C}$ for $15 \mathrm{~s}$ and $72^{\circ} \mathrm{C}$ for $15 \mathrm{~s}$. To confirm PCR product specificity, a melting curve was generated. The resulting $\mathrm{Ct}$ values were plotted against the $\mathrm{CFU}$ determined from the homogenized tissue.

Statistical analysis. GraphPad Prism 7 was used to analyze all data sets. Shown are either the mean and standard deviation (SD) or the median and the interquartile range as indicated in the figure legends. The two-tailed student's $t$-test or the Mann-Whitney test was used to test for statistical significances. $p$-values $\leq 0.05$ were considered significant, ${ }^{*} p \leq 0.05 ;{ }^{*} p \leq 0.01 ; * * * \leq 0.001$. Survival curves were compared using the Log-rank (Mantel-Cox) test.

Reporting summary. Further information on research design is available in the Nature Research Reporting Summary linked to this article.

\section{Data availability}

The RNAseq data that support the findings of this study are available at NCBI under BioProject accession number PRJNA714826 (https://www.ncbi.nlm.nih.gov/bioproject/ PRJNA714826). Source data are provided with this paper.

Received: 19 June 2020; Accepted: 28 May 2021; Published online: 23 June 2021

\section{References}

1. Huffnagle, G. B. \& Noverr, M. C. The emerging world of the fungal microbiome. Trends Microbiol. 21, 334-341 (2013).

2. Kim, J. \& Sudbery, P. Candida albicans, a major human fungal pathogen. J. Microbiol. 49, 171-177 (2011).

3. Brusselaers, N., Blot, S. \& Vogelaers, D. Deep-seated Candida infections in the intensive care unit. Neth. J. Crit. Care 15, 183-189 (2011).

4. Spellberg B., Marr K. A., Filler S. G. Candida: What should clinicians and scientists be talking about? In: Candida and Candidiasis, Second Edition). (American Society of Microbiology, 2012).

5. Horn, D. L. et al. Epidemiology and outcomes of Candidemia in 2019 patients: data from the prospective antifungal therapy alliance registry. Clin. Infect. Dis. 48, 1695-1703 (2009).

6. Perlroth, J., Choi, B. \& Spellberg, B. Nosocomial fungal infections: epidemiology, diagnosis, and treatment. Med Mycol. 45, 321-346 (2007).

7. Martin, R. et al. The Candida albicans-specific gene EED1 encodes a key regulator of hyphal extension. PLoS ONE 6, e18394 (2011).

8. Ernst, J. F. Transcription factors in Candida albicans - environmental control of morphogenesis. Microbiology 146, 1763-1774 (2000).

9. Cleary I. A. et al. Examination of the pathogenic potential of Candida albicans filamentous cells in an animal model of haematogenously disseminated candidiasis. FEMS Yeast Res. 16, https://doi.org/10.1093/femsyr/fow011 (2016).

10. Lorenz, M. C., Bender, J. A. \& Fink, G. R. Transcriptional response of Candida albicans upon internalization by macrophages. Eukaryot. Cell 3, 1076-1087 (2004).

11. Rooney, P. J. \& Klein, B. S. Linking fungal morphogenesis with virulence. Cell Microbiol 4, 127-137 (2002).

12. Thompson, D. S., Carlisle, P. L. \& Kadosh, D. Coevolution of morphology and virulence in Candida species. Eukaryot. Cell 10, 1173-1182 (2011).

13. Mukaremera, L., Lee, K. K., Mora-Montes, H. M. \& Gow, N. A. R. Candida albicans yeast, pseudohyphal, and hyphal morphogenesis differentially affects immune recognition. Front Immunol. 8, 629-629 (2017).

14. Saville, S. P., Lazzell, A. L., Monteagudo, C. \& Lopez-Ribot, J. L. Engineered control of cell morphology in vivo reveals distinct roles for yeast and filamentous forms of Candida albicans during infection. Eukaryot. Cell 2, 1053-1060 (2003)

15. Lo, H.-J. et al. Nonfilamentous C. albicans mutants are avirulent. Cell 90, 939-949 (1997).

16. Zheng, X., Wang, Y. \& Wang, Y. Hgcl, a novel hypha-specific G1 cyclinrelated protein regulates Candida albicans hyphal morphogenesis. EMBO J. 23, 1845-1856 (2004). 
17. Braun, B. R., Head, W. S., Wang, M. X. \& Johnson, A. D. Identification and characterization of TUP1-regulated genes in Candida albicans. Genetics 156, 31-44 (2000)

18. Braun, B. R., Kadosh, D. \& Johnson, A. D. NRG1, a repressor of filamentous growth in C.albicans, is down-regulated during filament induction. EMBO J. 20, 4753-4761 (2001).

19. Murad, A. M. et al. NRG1 represses yeast-hypha morphogenesis and hyphaspecific gene expression in Candida albicans. EMBO J. 20, 4742-4752 (2001).

20. Zakikhany, $\mathrm{K}$. et al. In vivo transcript profiling of Candida albicans identifies a gene essential for interepithelial dissemination. Cell Microbiol 9, 2938-2954 (2007).

21. Polke, M. et al. A functional link between hyphal maintenance and quorum sensing in Candida albicans. Mol. Microbiol 103, 595-617 (2017).

22. Allert, S. et al. Candida albicans-induced epithelial damage mediates translocation through intestinal barriers. mBio 9, e00915-e00918 (2018).

23. Felk, A. et al. Candida albicans hyphal formation and the expression of the Efg1-regulated proteinases Sap4 to Sap6 are required for the invasion of parenchymal organs. Infect. Immun. 70, 3689-3700 (2002).

24. Nucci, M. \& Anaissie, E. Revisiting the source of candidemia: skin or gut? Clin. Infect. Dis. 33, 1959-1967 (2001).

25. Miranda, L. N. et al. Candida colonisation as a source for candidaemia. J. Hosp. Infect. 72, 9-16 (2009).

26. Owari, M., Wasa, M., Oue, T., Nose, S. \& Fukuzawa, M. Glutamine prevents intestinal mucosal injury induced by cyclophosphamide in rats. Pediatr. Surg. Int 28, 299-303 (2012).

27. Koh, A. Y., Köhler, J. R., Coggshall, K. T., Van Rooijen, N. \& Pier, G. B. Mucosal damage and neutropenia are required for Candida albicans dissemination. PLoS Pathog. 4, e35 (2008).

28. Vautier, S. et al. Candida albicans colonization and dissemination from the murine gastrointestinal tract: the influence of morphology and Th17 immunity. Cell Microbiol. 17, 445-450 (2015).

29. Román, E., Huertas, B., Prieto, D., Díez-Orejas, R. \& Pla, J. TUP1-mediated filamentation in Candida albicans leads to inability to colonize the mouse gut. Future Microbiol. 13, 857-867 (2018).

30. Bowman, J. C. et al. Quantitative PCR assay to measure Aspergillus fumigatus burden in a murine model of disseminated aspergillosis: demonstration of efficacy of caspofungin acetate. Antimicrob. Agents Chemother. 45, 3474-3481 (2001).

31. Naglik, J., Albrecht, A., Bader, O. \& Hube, B. Candida albicans proteinases and host/pathogen interactions. Cell Microbiol 6, 915-926 (2004).

32. Du, H., Li, X., Huang, G., Kang, Y. \& Zhu, L. The zinc-finger transcription factor, Ofil, regulates white-opaque switching and filamentation in the yeast Candida albicans. Acta Biochim. Biophys. Sin. 47, 335-341 (2015).

33. Wakade R. S., Ristow L. C., Stamnes M. A., Kumar A., Krysan D. J. The Ndr/ LATS kinase Cbk1 regulates a specific subset of Ace2 functions and suppresses the hypha-to-yeast transition in Candida albicans. mBio 11, e01900-20 (2020).

34. Su, C., Li, Y., Lu, Y. \& Chen, J. Mss11, a transcriptional activator, is required for hyphal development in Candida albicans. Eukaryot. Cell 8, 1780-1791 (2009).

35. Hao, B. et al. Candida albicans RFX2 encodes a DNA binding protein involved in DNA damage responses, morphogenesis, and virulence. Eukaryot. Cell 8 627-639 (2009).

36. Ene, I. V. et al. Phenotypic profiling reveals that Candida albicans opaque cells represent a metabolically specialized cell state compared to default white cells. mBio 7, e01269-01216 (2016).

37. Kvaal, C. A., Srikantha, T. \& Soll, D. R. Misexpression of the white-phasespecific gene WH11 in the opaque phase of Candida albicans affects switching and virulence. Infect. Immun. 65, 4468-4475 (1997).

38. Tao, L. et al. Discovery of a "White-Gray-Opaque" tristable phenotypic switching system in Candida albicans: roles of non-genetic diversity in host adaptation. PLoS Biol. 12, e1001830 (2014).

39. McIlroy David, R., Wagener, G., Lee, H. T. \& Riou, B. Biomarkers of acute kidney injury: an evolving domain. Anesthesiology 112, 998-1004 (2010).

40. Sabbisetti, V. S. et al. Novel assays for detection of urinary KIM-1 in mouse models of kidney injury. Toxicol. Sci. 131, 13-25 (2013).

41. Leventhal, J. S. et al. Autophagy limits endotoxemic acute kidney injury and Alters renal tubular epithelial cell cytokine expression. PLoS ONE 11, e0150001 (2016).

42. Singer, $M$. et al. The third international consensus definitions for sepsis and septic shock (Sepsis-3). JAMA 315, 801-810 (2016).

43. Kadosh, D. Control of Candida albicans morphology and pathogenicity by post-transcriptional mechanisms. Cell Mol. Life Sci. 73, 4265-4278 (2016).

44. Desai, J. V. Candida albicans hyphae: from growth initiation to invasion. J. Fungi (Basel) 4, 10-19 (2018).

45. Böhm, L. et al. The yeast form of the fungus Candida albicans promotes persistence in the gut of gnotobiotic mice. PLoS Pathog. 13, el006699 (2017).
46. Witchley, J. N. et al. Candida albicans morphogenesis programs control the balance between gut commensalism and invasive infection. Cell Host Microbe 25, 432-443.e436 (2019).

47. Albac, S. et al. Candida albicans is able to use M cells as a portal of entry across the intestinal barrier in vitro. Cell Microbiol 18, 195-210 (2016).

48. Spellberg, B., Ibrahim, A. S., Edwards, J. E. Jr. \& Filler, S. G. Mice with disseminated candidiasis die of progressive sepsis. J. Infect. Dis. 192, 336-343 (2005).

49. Lionakis, M. S., Lim, J. K., Lee, C. C. \& Murphy, P. M. Organ-specific innate immune responses in a mouse model of invasive candidiasis. J. Innate Immun. 3, 180-199 (2011).

50. Wächtler, B., Wilson, D., Haedicke, K., Dalle, F. \& Hube, B. From attachment to damage: defined genes of Candida albicans mediate adhesion, invasion and damage during interaction with oral epithelial cells. PLOS ONE 6, e17046 (2011).

51. McKenzie, C. G. et al. Contribution of Candida albicans cell wall components to recognition by and escape from murine macrophages. Infect. Immun. 78, 1650-1658 (2010).

52. Blasi, E., Pitzurra, L., Bartoli, A., Puliti, M. \& Bistoni, F. Tumor necrosis factor as an autocrine and paracrine signal controlling the macrophage secretory response to Candida albicans. Infect. Immun. 62, 1199-1206 (1994).

53. Brown, A. J. P., Brown, G. D., Netea, M. G. \& Gow, N. A. R. Metabolism impacts upon Candida immunogenicity and pathogenicity at multiple levels. Trends Microbiol 22, 614-622 (2014).

54. Askew, C. et al. Transcriptional regulation of carbohydrate metabolism in the human pathogen Candida albicans. PLoS Pathog. 5, e1000612 (2009).

55. Sandai, D. et al. The evolutionary rewiring of ubiquitination targets has reprogrammed the regulation of carbon assimilation in the pathogenic yeast Candida albicans. mBio 3, e00495-00412 (2012).

56. Ballou, E. R. et al. Lactate signalling regulates fungal $\beta$-glucan masking and immune evasion. Nat. Microbiol 2, 16238-16238 (2016)

57. Childers, D. S. et al. The rewiring of ubiquitination targets in a pathogenic yeast promotes metabolic flexibility, host colonization and virulence. PLoS Pathog. 12, e1005566 (2016).

58. Ene, I. V., Brunke, S., AJP, Brown \& Hube, B. Metabolism in fungal pathogenesis. Cold Spring Harb. Perspect. Med 4, a019695 (2014).

59. Miramón, P. \& Lorenz, M. C. A feast for Candida: metabolic plasticity confers an edge for virulence. PLoS Pathog. 13, e1006144 (2017).

60. Meiller, T. F. et al. A novel immune evasion strategy of Candida albicans: proteolytic cleavage of a salivary antimicrobial peptide. PLoS ONE 4, e5039 (2009).

61. Gropp, K. et al. The yeast Candida albicans evades human complement attack by secretion of aspartic proteases. Mol. Immunol. 47, 465-475 (2009).

62. Schild, L. et al. Proteolytic cleavage of covalently linked cell wall proteins by Candida albicans Sap9 and Sap10. Eukaryot. Cell 10, 98-109 (2011).

63. Simpson, D. P. Citrate excretion: a window on renal metabolism. Am. J. Physiol. 244, F223-F234 (1983).

64. Kochanowski, K., Sauer, U. \& Noor, E. Posttranslational regulation of microbial metabolism. Curr. Opin. Microbiol 27, 10-17 (2015).

65. Leach, M. D. \& Brown, A. J. Posttranslational modifications of proteins in the pathobiology of medically relevant fungi. Eukaryot. Cell 11, 98-108 (2012).

66. Swidergall, M. et al. Candidalysin is required for neutrophil recruitment and virulence during systemic Candida albicans infection. J. Infect. Dis. 220, 1477-1488 (2019).

67. Angeletti S. et al. Plasma neutrophil gelatinase-associated lipocalin (NGAL) in combination with procalcitonin (PCT) and MR-proadrenomedullin (MRproADM) in the diagnosis and prognosis of sepsis and sepsis associated acute kidney injury. J. Immunol. Tech. Infect. Dis. 5, https://www.scitechnol.com/ peer-review/plasma-neutrophil-gelatinaseassociated-lipocalin-ngalincombination-with-procalcitoninpct-and-mrproadrenomedullinmrproadmin-the-d-mrMK.php?article_id=4674 (2016).

68. Horst, S. A. et al. Prognostic value and therapeutic potential of TREM-1 in Streptococcus pyogenes- induced sepsis. J. Innate Immun. 5, 581-590 (2013).

69. Boulanger, Y., Ghuysen, M.-S., Nchimi, A., Lewin, M. \& Khamis, J. Ultrasound diagnosis and follow-up of neonate renal candidiasis. J. Belg. Soc. Radio. 100, 113-113 (2016).

70. Banerjee, M. et al. UME6, a novel filament-specific regulator of Candida albicans hyphal extension and virulence. Mol. Biol. Cell 19, 1354-1365 (2008).

71. Spiering, M. J. et al. Comparative transcript profiling of Candida albicans and Candida dubliniensis identifies SFL2, a C. albicans gene required for virulence in a reconstituted epithelial infection model. Eukaryot. Cell 9, 251-265 (2010).

72. McCall, A. D., Kumar, R. \& Edgerton, M. Candida albicans Sfl1/Sfl2 regulatory network drives the formation of pathogenic microcolonies. PLoS Pathog. 14, e1007316 (2018).

73. Noble, S. M., French, S., Kohn, L. A., Chen, V. \& Johnson, A. D. Systematic screens of a Candida albicans homozygous deletion library decouple morphogenetic switching and pathogenicity. Nat. Genet. 42, 590-600 (2010). 
74. Saville, S. P., Lazzell, A. L., Chaturvedi, A. K., Monteagudo, C. \& Lopez-Ribot, J. L. Efficacy of a genetically engineered Candida albicans tet-NRG1 strain as an experimental live attenuated vaccine against hematogenously disseminated candidiasis. Clin. Vaccin. Immunol. 16, 430-432 (2009).

75. Saville, S. P., Lazzell, A. L., Chaturvedi, A. K., Monteagudo, C. \& Lopez-Ribot, J. L. Use of a genetically engineered strain to evaluate the pathogenic potential of yeast cell and filamentous forms during Candida albicans systemic infection in immunodeficient mice. Infect. Immun. 76, 97-102 (2008).

76. MacCallum, D. M. \& Odds, F. C. Temporal events in the intravenous challenge model for experimental Candida albicans infections in female mice. Mycoses 48, 151-161 (2005).

77. Odds, F. C., Van Nuffel, L. \& Gow, N. A. R. Survival in experimental Candida albicans infections depends on inoculum growth conditions as well as animal host. Microbiology 146, 1881-1889 (2000).

78. Yapar, N. Epidemiology and risk factors for invasive candidiasis. Ther. Clin. Risk Manag 10, 95-105 (2014).

79. Ho H.-1. \& Haynes K. Candida glabrata: new tools and technologiesexpanding the toolkit. FEMS Yeast Res. 15, fov066, https://doi.org/10.1093/ femsyr/fov066 (2015).

80. Bravo Ruiz, G., Ross, Z. K., Gow, N. A. R. \& Lorenz, A. Pseudohyphal growth of the emerging pathogen Candida auris Is triggered by genotoxic stress through the S phase checkpoint. mSphere 5, e00151-00120 (2020).

81. Sil, A. \& Andrianopoulos, A. Thermally dimorphic human fungal pathogenspolyphyletic pathogens with a convergent pathogenicity trait. Cold Spring Harb. Perspect. Med 5, a019794 (2014).

82. Nakayama, $\mathrm{H}$. et al. Tetracycline-regulatable system to tightly control gene expression in the pathogenic fungus Candida albicans. Infect. Immun. 68, 6712-6719 (2000).

83. Reuß, O., Vik, Å., Kolter, R. \& Morschhäuser, J. The SAT1 flipper, an optimized tool for gene disruption in Candida albicans. Gene 341, 119-127 (2004).

84. Gillum, A. M., Tsay, E. Y. H. \& Kirsch, D. R. Isolation of the Candida albicans gene for orotidine-5' $5^{\prime}$ phosphate decarboxylase by complementation of $S$. cerevisiae ura3 and E. coli pyrF mutations. MGG 198, 179-182 (1984).

85. Afgan, E. et al. The Galaxy platform for accessible, reproducible and collaborative biomedical analyses: 2018 update. Nucleic Acids Res. 46, W537-w544 (2018).

86. Love, M. I., Huber, W. \& Anders, S. Moderated estimation of fold change and dispersion for RNA-seq data with DESeq2. Genome Biol. 15, 550-571 (2014).

87. Skrzypek, M. S. et al. The Candida Genome Database (CGD): incorporation of Assembly 22, systematic identifiers and visualization of high throughput sequencing data. Nucleic Acids Res. 45, D592-D596 (2017).

88. Supek, F., Bošnjak, M., Škunca, N. \& Šmuc, T. REVIGO summarizes and visualizes long lists of gene ontology terms. PLOS ONE 6, e21800 (2011).

89. Shannon, P. et al. Cytoscape: a software environment for integrated models of biomolecular interaction networks. Genome Res 13, 2498-2504 (2003).

90. Han, Y. \& Cutler, J. E. Assessment of a mouse model of neutropenia and the effect of an anti-candidiasis monoclonal antibody in these animals. J. Infect. Dis. 175, 1169-1175 (1997).

91. Ermert, D. et al. Mouse neutrophil extracellular traps in microbial infections. J. Innate Immun. 1, 181-193 (2009).

\section{Acknowledgements}

We would like to thank Birgit Weber, Nadja Jablonowski, Stephanie Wisgott and Elisabeth Rätsch for excellent technical assistance. Furthermore, we want to thank all members of the Research Group Microbial Immunology (HKI) for technical support with the animal experiments as well as the Department of Microbial Pathogenicity Mechanisms (HKI) and Franziska Gerwien for encouraging discussions. The work was financially supported by the German Research Foundation (DFG; JA1960/1-1 to IDJ; and in part through the TRR 124 FungiNet, "Pathogenic fungi and their human host: Networks of Interaction," DFG project number 210879364, Project C5 to IDJ and B2 to TD). CD was supported by the International Leibniz Research School for Microbial and Bimolecular Interactions (ILRS). M.S. was supported in part by NIH grant R00DE026856.

\section{Author contributions}

Conception and design of the study was performed by C.D., M.P. and I.D.J. All authors contributed with data acquisition and analysis: C.D., M.P., B.S., K.S., S.R., A.E.G., T.P., S.S., R.M. and I.D.J. were involved in animal experiments; T.P. and A.G. performed epithelial coinfections; C.D. and B.S. performed flow cytometry; M.S. performed immunohistochemistry; C.D., K.S. and M.J.N. performed neutrophil experiments. C.D. and K.S. prepared samples for RNAseq. J.P.P. and T.D. performed differential gene expression analysis. Data were interpreted by C.D., M.P., B.S., T.P., M.S., S.R., A.E.G. and I.D.J. C.D. and I.D.J. wrote and all authors commented on the manuscript.

\section{Funding}

Open Access funding enabled and organized by Projekt DEAL.

\section{Competing interests}

The authors declare no competing interests.

\section{Additional information}

Supplementary information The online version contains supplementary material available at https://doi.org/10.1038/s41467-021-24095-8.

Correspondence and requests for materials should be addressed to I.D.J.

Peer review information Nature Communications thanks the anonymous reviewers for their contribution to the peer review of this work. Peer reviewer reports are available.

Reprints and permission information is available at http://www.nature.com/reprints

Publisher's note Springer Nature remains neutral with regard to jurisdictional claims in published maps and institutional affiliations.

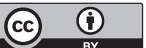

Open Access This article is licensed under a Creative Commons Attribution 4.0 International License, which permits use, sharing, adaptation, distribution and reproduction in any medium or format, as long as you give appropriate credit to the original author(s) and the source, provide a link to the Creative Commons license, and indicate if changes were made. The images or other third party material in this article are included in the article's Creative Commons license, unless indicated otherwise in a credit line to the material. If material is not included in the article's Creative Commons license and your intended use is not permitted by statutory regulation or exceeds the permitted use, you will need to obtain permission directly from the copyright holder. To view a copy of this license, visit http://creativecommons.org/ licenses/by/4.0/.

(c) The Author(s) 2021 